\title{
DIE TĚNGGĚRESEN.
}

EIN ALTER JAVANISCHER VOLKSSTAMM.

\section{Ethnologische Studie}

VON

J. H. F. KOHLBR UG;GE. 


\section{N H A L T.}

I. Einleitung.

II. LAGe.

III. Literaturquellen.

IV. Geschichte.

V. SAGEN.

Vi. Bau u. Einrichtung der Wohnung.

VII. Algemeine Sitten.

VIII. ManN UNd WeIb.

a. Hochzeit

l. RechtsverhäLtisisse in der Ehe.

c. Ehescheidung.

d. Schwangerschaft und Arbeit der Frau.

IX. Das Kind.

X. Eltern, Erbrecht, Adoption.

XI. Gebräuche bei Todesfällen.

Begräbnis u. Toutenfeier.

XII. Gottesdienst.

XIII. Feste.

a. Feste, welche an bestimmten Tagen gefeiert WERUEN.

b. Bromofest. 


\section{Einleitung.}

Das Tĕnggĕrgebirge gab den Tĕnggĕresen seinen Namen, sie selbst nennen sich "Wong Tĕnggĕr". In der Literaturübersicht (Seite 87) findet man den Titel einer Anthropologischen Studie, in der ich nachgewiesen habe dass die Tĕnggĕresen ihrem Körperbau nach Urmalaien sind (Hagen), oder was dasselbe ist Indonesier (Hamy); man möge dabei aber nicht an Polynesier denken, die meiner Meinung nach von den Indonesiern zu trennen sind. Als Indonesier gehören sie im anthropologischen Sinne zu den älteren d. h. reineren Stämmen ${ }^{1}$, aber auch sie haben lange unter dem Einfluss der Hindus gelebt, von deren Glaubensformen sie also sehr influenciert worden sind, und zwar ganz. besonders durch den Sjiwaismus, weniger, viellicht gar nicht durch den Buddhismus. Der Sjiwaismus hat sich dabei in ihrem Geiste mit dem Indonesischen Heidentum gemischt. Der Einfluss des Islam ist erst so recenten Datums, dass es meist gelang die hierdurch hervorgerufenen Umänderungen scharf von den alten Tĕnggĕrschen Gebräuchen zu trennen. Übrigens kann man sie, den Sitten nach, und das beweisen die nachfolgenden Blätter, kurzweg als "Javanen" bezeichnen, denn von diesen unterscheiden sie sich nur dadurch dass sie alte Gebräuche, alte Sprachformen reiner bewahrten und diese wieder selbstständig umbildeten da sie einige Jahrhunderte ganz isoliert lebten. In mancher Beziehung kann man also aus den Gebräuchen und Sitten der Těnggĕrezen das Leben der Javanen während der heidnischen Vorzeit reconstruieren, darum ist eine eingehende Beschreibung dieses Volkes gewiss gerechtfertigt.

\section{Lage.}

Es liegt das Tĕnggĕrgebirge in Ost-Java, dort wo die Insel am schmalsten ist; die eine Hälfte des Gebirges gehört zur Resident-

1 Man nimmt nämlich an, dass die mehr langköpfigen Indonesier einst den Malaiïschen Archipel bewohnten und sich erst später mit einer breitköpfigen Rasse der "Maleischen" innig mischten. 
schaft Pasuruan, die andere zu Probolinggo. Obgleich dem Gebirge Hochflächen gänzlich fehlen, so eignen sich die vielen sanft von dem centralen Krater (Bromo) abfallenden Bergrippen doch sehr zur Bepflanzung; an anderer Stelle habe ich nachgewiesen, dass der Boden ganz besonders fruchtbar und das Klima auffallend regelmässig und angenehm ist (sieh : Anm. bei Literaturquellen S. 87). Es ist also leicht erklärlich, dass sich in dieser Höhe (16002000 meter) auf diesem Gebirge Menschen anpflanzten und glücklich lebten, während die anderen Kegelberge Java's meist nur Urwälder zeigten ${ }^{1}$.

Es is jetzt, da der Islam seit mehr als einem Jahrhundert sich bestrebt die Eigenart der Tĕnggĕresen zu unterdrücken, keine leichte Sache zu bestimmen, welche Ortschaften noch von reinen Tĕnggerrezen bewohnt werden, da sie sich äusserlich nur wenig von anderen Javanen unterscheiden, darum will ich hier nur diejenigen Dörfer nennen, deren Bewohner auch jetzt noch vom Oberpriester aufgerufen werden, um sich an ihrem Hauptfest "dem Bromofeste" zu beteiligen, wobei man beachten muss, dass die kleineren Gehöfte, da sie keine eigenen Priester haben, auch keine direkte Aufrufung erhalten ${ }^{2}$. Diese Dörfer sind folgende:

In der Residentschaft Pasuruan; A. Distrikt Tĕngĕr: Tosari ('Telogosari, Kertanom, Wonomerto, Wonosunjo, Ledok), Purwono (Baledono), Sedaheng (Wonokitri, Keduwung), Porlokoyo, Ngadiwono, Ngadiredjo oder Tjemorogading (Kletak, Kaju Kebek, Wonosengkoro), Mororedjo (Kali Tedjo, Kandangan) ${ }^{3}$.

B. Distrikt Tumpang: Ngadlas, Gubug Klakah, Tosari, Ngduwut Pontjo Kesumo, Besuki, Pandansari, Sumber Tjillong, Sumber Redjo, Dahuan.

1 Das Gebirge wird durch zahllose Rippen gebildet, die von einem Rückgrat des centralen Kraters nach allen Seiten ausstrahlen. Dieser Krater ist der grösste der Welt, er bedeckt fast eine Quadratmeile. Man nennt diesen Krater wobl am besten "Tĕnggĕr" und nicht "Bromo", denn dieser mehr bekannte Name muss für einen jüngeren Eruptionskegel reservirt werden, der sich in der Fläche des alten erloschenen Kraterbodens (das Sandmeer) erhebt. Man zählt vier solcher Eruptionskegel, von denen nur einer, „der Bromo", noch wirksam ist.

' Im nachfolgendem Verzeichnis wurden die Hauptdörfer cursiv gedruckt, die Weiler in Klammern erwähnt, so weit mir deren Namen bekannt waren.

${ }^{3}$ An Mororedjo schliessen sich an: Nongkodjadjar oder Kebonsari, Pajaman oder Handonosari u. s. w., deren Bewohner jetzt aber alle zum Islam bekehrt worden sind. 
In der Residentschaft Probolinggo. A. Distrikt Sukapura: Ngadisari, Wonotoro, Djetak, Putus, Ngadas, Wonokerso, Terbek, Lerlok-ombo.

B. Distrikt Lumadjang: Lnmailjang, Kandangan.

\section{Literaturquellen.}

Diese wurden bereits durch Veth in dritten Bande (1882) seines bekannten Buches über Java gesammelt, alles wichtigere findet man $\operatorname{dort}^{1}$; denn es sind die ältesten Berichte die wertvollsten, da sie verfasst wurden, als die Tĕnggĕresen ihre Sitten unter dem Einfluss des Islam noch wenig geändert hatten. Ich habe diese älteren Berichte denn auch vielfach zu den vorliegenden Beschreibungen benutzt, ich habe sie stets mit den heutigen Zuständen, den heutigen Abänderungen verglichen und ihre Verlässlichkeit durch Nachfrage bei den ältesten Bewohnern und in den weit abseits vom grossen Verkehrswege gelegenen Dörfern geprüft. Anderseits konnte ich, was ich selbst sah und hörte, durch diese älteren Mitteilungen controlieren, die Controversen werden in den nachfolgenden Blättern aber meist verschwiegen, ich gab eben nur das, was ich für richtig hielt. Leider befassen sich die älteren Quellen meist nur mit einigen Sitten und Festen; der eine Reisende achtete nur auf dieses, der andere nur auf jenes; ich habe alles gesammelt, geordnet und mit meinen eiguen Beobachtungen zu einem Ganzen vereinigt, wobei ich versuchte auf alles zu achten was ethnologisch interessant sein könnte. Aber nicht in allen Teilen des Gebirges kinnte ich längere Zeit verweilen, ganz genau kenne ich nur die Bewohner der Nordseite des Gebirges, in deren Mitte ich sieben Jahre lebte; darum hoffe ich dass später ein anderer Forscher untersuchen wird ob vielleicht in den Dörfern der Ost- und Westseite sich Abweichungen von den hier beschriebenen Gebräuchen finden, doch kenne ich sie übrigens so weit, dass ich versichern kann, dass die Unterschiede nicht gross sein können. Auch giebt es noch eine andere Quelle, welche ich, der alten Sprache und Schrift unkundig, ganz uubeachtet lassen musste. Fast jeder Priester und auch mancher einfache Dorfbewohner besass

1 Da Veth's Buch wohl jedem Forscher zur Verfügung steht, so scheint es mir überflüssig die Liste der Schriften hier wieder zu geben. Die im Text erwähnten Autoren finden sich bei Veth, 1. c. III, S. 1008-1009. 
nämlich früher (und einige heute noch) alte Schriften auf Lontarblättern, welche Gebetsformeln u. s. w. enthalten. Die meisten dieser alten Handschriften sind jetzt nach Leiden oder Batavia gewaudert, aber leider noch nicht entziffert worden. Es könnte sein dass in diesen, obgleich sie meist Gebete enthalten, sich noch einiges über den Glauben und die Sitten dieses Volkes wird finden lassen, die wohl auch darum so schnell sich änderten, weil keiner ihrer Priester die Schriften mehr lesen konnte; was die Priester der Jetztzeit wissen beruht nur auf mündlicher Überlieferung von Vater auf Sohn und Enkel. Thre eignen Gebete sind ihnen heute zum Teil unverständlich geworden, manches mag auch wohl durch Verwechselung ähnlich klingender Worte jede Bedeutung verloren haben. Doch habe ich mich bemüht die hauptsächlichsten dieser zum Teil unverständlichen Gebetformeln zu sammelu um sie vor völligem Untergang zu retten. Diese, wie die Wechselgespräche bei der Heirat und beim Todtenfest habe ich als Manuseript der wissenschaftlichen Gesellschaft in Batavia überreicht (Bataviaasch Genootschap). Ethnologisch bieten sie wohl nichts Bemerkenswerthes, zum Theil kann man sie als reinen Unsinn bezeichnen, was natürlich ist, da man nicht mehr auf den Inhalt sondern nur noch auf den Klang achtet.

Was später (nach Veth) noch über die Tĕnggĕresen geschrieben wurde ${ }^{1}$ ist meist von geringem Werth. Ich gab früher zwei kurze Mittheilungen heraus, die ich weiter unten eitieren werde, soust erschienen meist nur Reisebeschreibungen, Landschaftsskizzen, Charakterisierungen der Bevölkerung von Turisten aus allen Ländern Europa's, die alle diese jetzt sehr bekaunte und schöne Gegend als Reisende oder als Kranke zur Heilung besuchten; es haben diese Mitteilungen natürlich keinen wissenschaftlichen Wert. Eine rühmliche Ausnahme bilden nur die so kurz gehaltenen Angaben von W. de Wolff van Westerrode, die unter dem Titel "Aanteekeningen op Veth's Java Deel IIl“ in der Tijdschrift van het K. Nederl. Aardrijkskundig Genootschap erschienen sind (Th. XII. ]895); auch vermehrte Herr H. M. la Chapelle unlängst unsere Kenntnis hiesiger Alterthümer. Weiter veröffentlichte ich eine Reihe Arbeiten, in denen diese Gegend anthropologisch, zoologisch und

1 In seiner Literaturübersicht hat Veth die sehr wichtige aber allerdings sehr seltene Schrift Hageman's übersehen: Tengger-Gebergte en bevolking. Pasoeroean 1871. 
meteorologisch ausgebeutet wurde, deren Inhalt aber nicht hierher gehört ${ }^{1}$.

Aus Obigem geht genügend hervor, dass man nicht erwarten darf noch heute in einem beliebigen Dorfe alle die Gebräuche und Sitten wieder zu finden, welche in den nachfolgenden Seiten beschrieben werden. Vieles haben die Bewohner vergessen oder abgeändert nach javanischem Vorbilde; die Eigenart des Volkes schwindet mehr und mehr; noch einige Jahrzehnte und es wird sich kaum mehr von den es umringenden Javanen unterscheiden.

\section{Geschichte.}

Von der alten Geschichte dieses Volkes wissen wir leider nur sehr wenig, doch gelangte man unlängst in den Besitz eines Dokumentes, welches, wie kurz auch sein Inhalt ist, doch zeigte, dass die Volkssagen uns auf einen ganz unrichtigen Weg gebracht hatten. Dieses Dokument war eine kupferne Platte mit Inschrift, die durch Herrn la Chapelle in einem Hause entdeckt wurde, wo sich auch noch ein schöner Lingga fand. Beide hatte man in einem Acker gefunden. Die Inschrift, welche durch Hernn Dr. Brandes entziffert wurde, giebt kund: "Dass der Fürst Hyang Wĕkasing Suka alle Bewohner des Dorfes Walandit von einer gewissen Steuer befreit, weil dieses Dorf ein heiliges Dorf ist, denn seine Bewohner sind Gottesdiener des heiligen Berges Bromo." ${ }^{2}$

Die Platte trug ein Datum, welches, unserm 21 en Juni 1405 gleichzusetzen ist. Das Dorf Walandit liegt noch heute am Fusse

1 Ich will hier nur kurz die Titel nennen:

L'anthropologie des Tenggerois, indonésiens-montagnards de Java: L'anthropologie. T. IX. Paris. 1897.

Immunité phtisique dans les hautes régions et sa cause: Natuurk. Tijdschrift voor Nederl. Indie. D. LV. afl. 3. 1896.

Action du elimat des tropiques et du climat d'altitude sur le sang de l'homme: Geneesk. Tijdschr, voor Ned. Indie. D. XXXV. afl. 5 en 6. 1895.

Die Krankheiten eines Bergvolkes der Insel Java: Janus, Archives internationales pour l'histoire de la médecine et pour la géographie médicale. 1897.

Zoogdieren van den Tengger: Natuurk. Tijdschrift voor Ned. Indië. Deel LV, afl. 3. 1896.

Meteorologische waarnemingen te Tosari. Het klimaat van den Tengger vergeleken met dat van andere bergen in tropische gewesten: Natuurk. Tijdsehrift voor Nederl. Indie. D. LVIII. blz. 400. 1898.

2 Ich gebe hier nur den Hauptinhalt. Die Übersetzung findet sich in den Notulen v. h. Bataviaasch Genootschap, 1899, S. 62 und 64--69. 
des Tĕnggĕrgebirges, die damaligen Bewohner desselben würden wir heute also als Tĕnggĕresen bezeichnen. Auch in einem älteren Gedichte wird der Name dieses Dorfes erwähnt und kann man nach Brandes daraus den Schluss ziehen: dass der Berg Bromo bereits zu Ende des vierzehnten Jahrhunderts als heilig verehrt wurde und dass die Tĕnggerresen damals schon eine isolirte Stellung einnahmen, obgleich sie übrigens den Javanen zuzurechnen sind.

Andere Alterthümer, die man bei den Tĕnggĕresen fand, weisen zum Teil noch weiter zurück. So die bronzenen Becher (Zodiakbecher), welche die Priester benutzen (sieh unten), die alle im dreizehnten Jahrhundert angefertigt worden sind, wodurch dem Volke ein Alter von 6 Jahrhunderten zugesichert ist. Eine Annamitische Münze war von Lie-loi dem Rebellen, 1417-1426; ein bronzener Lingga zeigte Modjopahitsche Arbeit, das Reich Modjopahit fiel vor vier Jahrhunderten vor dem Ansturm des Islam.

Betreten wir jetzt den Boden der neueren Geschichte, welche mit dem Erscheinen der Europäer auf Java anfängt, so werden wir auch hier nur wenige beglaubigte Nachrichten finden.

Es gehören die meisten Tĕnggĕresen zur Residentschaft Pasuruan, ihre Geschichte wird also mit der dieses Teiles der Insel Java verknüpft sein. Der Hauptort Pasuruan (Javanisch: Gembong) wird in der Geschichte erst dann häufiger erwähnt, als der geflüchtete Sklave Suropati dort 1686 ein eignes Reich gegründet hatte. Es gehörte diese Gegend übrigens zum Mataramschen Reich ${ }^{1}$, welche Thatsache vielleicht zu der Sage der Tĕnggĕresen Anlass gab, die ihre Herkunft nach Mataram verlegt. Wir haben oben gesehen dass dieses Volk weit älter ist als das Mohamedanische Reich Mataram. Die andere Sage (man erzählte sie noch in 1785 an Adr. van Rijek), nach welcher man den Stammort der Tĕnggĕresen in Bantam suchen muss, ist vielleicht folgender Weise entstanden: Suropati flüchtete von Bantam nach Mataram und von dort nach Ost-Java, vielleicht gab er den Tĕnggĕresen ueue Häuptlinge aus seinem Gefolge, die vermutlich aus Bantam stammten. Die Erklärung einer Sage bleibt übrigens stets unsicher, kehren wir darum zur Geschichte zurück ${ }^{2}$.

1 Das grosse Reich in Mitten-Java, welehes zeitweise die ganze Insel ausser der Westküste (Bantam) unterwarf.

2 Die nachfolgende Beschreibung schliesst sich an die neue Auflage von Veth's "Java", Theil II an und an die in der ersten Auflage citierten Schriften, besonders auch an die oben bereits erwähnte Schrift Hageman's. 
Als Suropati durch den Fürsten von Mataram und die Niederländer besiegt worden war (Schlacht bei Bangil) blieben seine Nachkommen im Besitz des südlichen, gebirgigen Teils von Pasuruan, beunruhigten von dort aus das umliegende Land (die Küsten und Kediri mit Blitar) durch ihre Raubzüge, zogen sich aber vor ihren Verfolgern stets in das damals fast unzugängliche Gebirge von Malang und Ngantang zurück.

Es scheint dass das Tĕnggĕrgebirge zunächst noch von ihnen verschont blieb, denn 1733 wurde der von ihnen aus Malang vertriebene Ingebei Sutodjåyå durch den Susuhunan von Mataram zum Bopati (Regent) von Tĕnggèr angestellt; Hageman glaubt, dass dieser die ersten Kaffeepflauzungen im Tĕnggĕr-Gebirge anlegte (mit Kaffeegärten ist heute der untere Teil des Gebirges bedeckt) und zwar zu eignem Nutzen, denn Anptlanzungen für den Handel waren damals auch in Mataram verboten.

Der Hauptort Pasuruan mit der Küste wurde 1743 durch Mataram an die Niederländische Compagnie abgetreten, die dort ein€n Kommandanten anstellte, der mit militärer und civiler Macht bekleidet war. Der südliche Theil "Malang und Ngantang" verblieb unter einem eignen Regenten dem Hause Mataram; allerdings nur dem Namen nach, da die Söhne Suropati's dort eine Gewaltherrschaft ausübten und sich auch mit den Tĕnggĕresen verbündeten. Ein Enkel Suropatti's Wirå negårå half den Fürsten von Madura Tjakra-ning-Rat, der auch Pasuruan belagerte, und vielleicht war es um diese Zeit, dass die Tĕnggĕresen den Kriegszug nach eïner Insel machten von der ihre Sage erzählt '. Stets war das Gebiet der Söhne Suropati's, die auch Lumadjang besetzten, der Zufluchtsort aller Aufrührer aus Mataram. Wirå negårå starb 1763. Thm folgte sein Bruder Malaju Kusumå, der zusammen mit Ngabĕhi Sutå Widjåjå 2, dem Anführer der Tĕnggĕresen, im

I Im „Kort verhaal van de Javasche oorlogen sedert den jare 1741 tot 1757" wird der Krieg eines Tapa gegen den Fürsten von Madura (Bangkalan) erwähnt, letzterer wurde dabei understützt durch Truppen aus Pasuruan, die sich nach Pamekasan (Madura) begaben, vielleicht waren unter diesen auch Tenggeresen (Vergl. die Sage S. 100).

2 Man achte auf die Übereinstimmung dieses Namens mit dem des obengenannten: Ingebei Sutådjåyå (Ngaběhi und Ingebei sind übereinstimmende Adelstitel), entweder handelt es sich hier um denselben Mann, der dann ảus einem Feinde zum Bundesgenossen wurde, oder Sutå Widjåjå ist der Sohn Sutådjåyås: Die Javanen benutzen häufig den ersten Teil ihres Namens um den Namen des Sohnes zu bilden, änderen dann aber stets den zweiten Teil. 
Jahre 1764 und während der folgenden Jahre Raubzüge nach der Küste von Pasuruan und Surabaya unternahm. Sie wurden vom Kominandanten des Forts Pasuruan bei Porrong besiegt. Dieser Kommandant, der C. L. Troponegro, hiess nahm einen hervorragenden Antheil an der Eroberung der Ostspitze Java's im Jahre 1767. Von dort aus zog er mit seinen Truppen wieder westwärts um sich mit den Truppen aus Mataram zu vereinigen, die gegen die Nachkommen Suropati's in Lumadjang und Malang zu F'elde gezogen waren. Erst unterwarf Troponegro ${ }^{1}$ Lumadjang, dann zog er an der Südseite des Smeru entlang nach der Gegend von Malang, dort wurden die alten Räuber von allen Seiten eingeschlossen, denn der Commandant von Pasuruan Gondelag ${ }^{2}$ zog ilım voin Norden her zur Hülfe, während der Ausweg nach dem Westen durch die Truppen aus Mataram besetzt worden war; im Süden lag das Meer.

Bei dem rein 'Tĕnggĕresischen Dorfe Gubug Klakah kam es 1768 zur heissen Schlacht, Malaju Kesumo wurde vollständig besiegt; wahrscheinlich beteiligten sich an dieser Schlacht auch die Tĕnggĕresen. Nachdem nun die Compagnie ganz Malang und Ngantang unterworfen hatte, hätte sie diese Länder deın Susu. hunan zurück geben müssen, da nur alles, was östlich von Pasuruan lag der Compagnie zugesichert worden war (Vertrag 1743), also auch der grösste Teil des Tĕnggĕrgebirges; aber man behielt einstweilen diese Länder und gab sie erst viel später dem Susuhunan zurück. Malang und Ngantang erhielten einen eignen Regenten.

Im Jahre 1772 wurde Adriaan van Rijck Kommandant von Pasuruan, er vertrieb 1776 die Seeräuber an der Südküste besonders von den Insel Nusa barung und Pulu sempu. Im Jahre 1785 schrieb er einen kurzen Bericht über die Sitten und Gebräuche der Tĕnggĕresen: die ältesten Nachrichten die wir von diesem merkwürdigen Volke besitzen.

1 Troponegro oder Trappannegro.

9 Gondelag war der Nachfolger Ram's, der an die Stelle Troponegro's trat, als dieser mit der Leitung des Kriegszuges betraut wurde. Unter Ram's Leitung sollen nach Hageman die ersten Gemüse im Těnggĕrgebirge gepflanzt worden sein; er war Kommandant von 1765-1768. - Gemüsepflanzungen bedecken jetzt den oberen Teil des Gebirges, ganz Ost-Java wird durch diese Pflanzungen mit Gemüsen und Kartoffeln versorgt und die Schiffe exportieren sie nach entfernten Inseln. 
Es soll auch das Landhaus "Tosari" gebaut haben (1787 oder früher nach Hageman) um dort für eignen Bedarf Gemüse zu pflanzen; es blieb bis 1867 Eigentum der Commandanten, später Residenten von Pasuruan. Einige Jahre später (1790 oder 1792) wurde van Rijek abberufen um im Kriege gegen Mataram zu helfen. 1794 wurde der Regent vou Malang und Ngantang abgesetzt und diese Länder dem tüchtigen Regenten von Bangil zugeteilt. 1811 gab Marschall Daendels Malang und Ngantang dem Susuhunan zurück, wofür er von diesem andere Landstriche in Mitten-Java erhielt.

Aber schon am Ende desselben Jahres wurden die genannten Landesteile dem Susuhunan durch Raffles wieder entrissen, der sie 1813 mit Pasuruan zu einer Residentschaft vereinigte; was sich bis auf unsere Tage erhalten hat.

Nach der Wiederherstellung der Niederländischen Herrschaft wurde Lawick van Pabst Resident von Pasuruan, er stellte den ersten Demang-Distrikt über die Tĕnggĕrezen an.

Verlassen wir jetzt den Boden der amtlich beglaubigten Geschichte und erkundigen wir uns nach dem, was uns die Tĕnggĕresen erzählen können, ohne aber ihre eigentlichen Sagen zu beachten.

Der oben erwähte "Demang" wohnte im Dorfe Tosari ganz in der Nähe des Landhauses der Residenten. Dort hatten aber die alten Häuptlinge nicht ihren Sitz gehabt. Der lag weiter südwestlich ganz in der Nähe des Dorfes Ngadiwono. Über diese Häuptlinge berichtet Hageman nach mündlichen Mitteilungen der Bevölkerung. Der erste hier Hemah Kellopo und sein Weib Endang Donosari, sie wohnten im Walde Purbowiseso nord-östlich von Ngadiwono, jetzt findet man dort keine Wohnstätten mehr. Von diesem Hemah Kellopo sollen die alten Kleider stammen, welche man in einem grossen Köcher verwahrt und nur einmal im Jahre beim Karofest (sieh dort) dem Volke zeigt, jetzt schreibt der Priester sie allerdings Bathoro guru zu. Die Nachfolger dieses Häuptlings waren: Kjahi Monjok, Kjahi Djolopo der erste und zweite, Kjahi Tumpo, Kjahi Piti, alle wohnten in Tjemoro gading (Ngadiredjo), ein grosses Dorf süd-westlich von Ngadiwono. Der siebente und letzte Häuptling war Kjahi Suranolio, dieser bewohnte Handonosari (jetzt Pajaman) westlich von Tjemoro gading. Ihm folgte 1818 der erste Demang-Distrikt, wie oben erwähnt wurde. Es lag im vorigen Jahrhundert der Mittelpunkt der Bevölkerung also weiter süd-westlich als heute, das geht nicht nur aus den Wohnorten 
dieser Häuptlinge hervor ${ }^{1}$ sondern auch aus der Thatsache, dass die ersten Kaffeepflanzungen dort (bei Nongkodjadjar und Pajaman) lagen (Kebon Bendoro und Kebon Singolangu), deren Alter man nach den riesigen Kaffeebäumen auf hundert sechzig Jahre schätzt. Wurden sie von dem oben genannten Ingebei Sutådjåyå gepflanzt, wie Hageman behauptet, dann ergiebt sich das ganz natürliche Verhältnis, dass der Representant des Susuhunan in derselben Gegend wie die Häuptlinge wohnte, welche schon damals mit dem Hauptort Malang durch einen Weg verbunden war.

Dass den von der Regierung ernannten Deınang's Tosari als Wohnort angewiesen wurde lässt sich wohl dadurch erklären dass dort das Landhaus und die Gemüsepflanzungen der Residenten lagen, während die einzig schöne Lage dieses Dorfes den Platz für das Landhaus anwies. Der erste Demang war Ardi-Judo, die Würde war erblich, ihm folgte sein Sohn Di Judo, dann Di Djojo und Ardi djojo. Ardi djojo war der letzte Demang, nach seinem Tode wurde dieser Titel abgeschafft und ein Wedono angestellt. Gleich der erste war ein Fremder "Dipo Djojo" genannt, aber nicht lange blieben diese Beamten auf Tosari wohnen, denn der Ort war zu weit von der Hauptstadt Pasuruan entfernt, ihr Sitz wurde darum bald nach Puspo und schliesslich nach Pasrepan verlegt.

Aber noch lange wurde die Gegend bei Ngadiwono, wo die ẹrsten Häuptlinge gelebt hatten, als eine geweihte, von den Tĕnggĕresen geschätzt. Darum liess sich der Demang Di Judo zu Tjemoro gading und Di djojo auf Tungu wulung (bei dem obengenannten Purbowiseso) begraben. Die Nachkommen dieser Demangs leben noch heute; es war nämlich Sitte dass der Demang, wenn er alt geworden war, sein Ambt niederlegte aber bis zu seinem Tode Dukun und zwar erster Dukun (Oberpriester) des Gebirges blieb. So geschah es mit Ardi Judo, Di Judo und Di Djojo. Der letzte Dernang Ardi Djojo legte aber vor seinem Tode auch das Ambt des Dukuns nieder und verheiratete sich nach Nongodjadjar wo er starb und begraben wurde. Als Oberpriester folgte ihm sein Bruder Pak Raman, dieser hatte zwei Söhne, der eine wurde Dukun von Ngadiwono, der andere ist der gegenwärtige Oberpriester und wohnt zu Tosari (Wasiman, alias Pak Ratio). Er wäre also der fünfte aus dewı Geschlecht der Demang's, damit ist er aber nicht

1 Auch das zu Anfang genannte Dorf Walandit liegt in jener Gegend, ist heute aber nur ein kleines Gehöft. 
zufrieden, denn er theilte mir mit, dass sein Stammbaum weit älter sei als 1818. Er behauptet der $20^{\text {te }}$ seines Geschlechtes zu sein, welches von Kjahi Tunggak und Njahi Monjok abstammen soll; diese Stammeltern wohnten auf Tungu wulung, und da dieses neben dem früheren Wohnorte (Purbowiseso) des ersten, dem Namen nach bekannten, Häuplings liegt, so wird dadurch die Abstammung dieses Priesters und also auch der Demangs von den âltesten Häuptlingen wahrscheinlich gemacht; da nun weiter die Priester aller Dörfer des ganzen Gebirges unter einander (also auch die von Sukapura und Tumpang) verwandt sind, zu demselben Priestergeschlecht gehören, und es nicht wahrscheinlich ist, dass ein Dorf je ohne Dukun war, so sind wahrscheinlich alle jetzt so weit von einander entfernten Dörfer als Volkspflanzungen von dem einen alten Mittelpunt, der bei Ngadiwono lag, ausgegangen. Wie wir gesehen haben zeigt das Geschlecht der Demaugs also fünf Representanten für das $19^{\mathrm{e}}$ Jahrhundert, rechnet man in gleicher Weise fünf auf jedes vorhergehende Jahrhundert, und ist die Angabe richtig, dass der jetzt lebende Priester der zwanzigste seines Geschlechtes ist, dann würde diese Familie also vier Jahrhunderte alt sein. Vor vier Jahrhunderten fiel das Reich Modjopahit vor dem Ansturm der Mohamedaner, vielleicht stammt das Geschlecht von einem der geflüchteten Modjopahitschen Fürsten, und würde die Sage von der Flucht vor dem Islam nach der Zerstörung von Modjopahit hierdurch erklärt sein. Also nicht die Tĕnggĕresen selbst, die damals das Gebirge schon lange bewohnten, sondern ihr Priestergeschlecht wäre dann von Modjopahitscher Herkunft.

\section{Sagen.}

I. Reang und Ingsun, oder die verschiedene Herkunft der Weiber und Männer ${ }^{1}$.

Im Tĕnggĕrgebirge lag ein Reich, dessen Hauptort Masangan war (jetzt verschwunden, aber die Stätte wird noch gezeigt) und an dessen Spitze ein Pambesar oder Panggedé stand, den das Volk Kjahi gedé Tĕnggĕr nannte. Die Tĕnggĕresen kleideten sich damals noch mit Baumrinde und assen nur Pflanzen. Einer ihrer Pambesars zog mit seinem Volke auf Flössen von Holz und Bambu nach einer benachbarten Insel, um deren Bewohner zu bekriegen.

1 Nach handschriftlichen Aufzeichnungen von Herrn H. M. la Chapelle. 
die das Fleisch aller Thieren assen, einige auch Menschenfleisch nicht verschmähten.

Nach dem Kriege brachte der Sohn des Anführers einen Teil seines Volkes mit den Gefangenen der Insel nach dem Tĕnggĕrgebirge zurück.

Die letzteren liessen sich nicht auf Masangan nieder, sondern in Wonosekar, einem jetzt verschwundenen Dorfe, welches früher unterhalb Wonokitri lag. Die Gefangenen benutzten für das Wort "Ich" das Wort "Ingsun", während der Tenggerese "Reang" sagte. Als Kriegsbeute hatte der Häuptlingssohn auch einige Elephanten mitgebracht. Eines Tages fiel einer dieser Elephanten in die Sungei Kretek und als den Leuten von Wonosekar befohlen wurde das Tier heraus zu holen verbargen sie sich, sodass in Wonosekar nur Weiber und Kinder zurück blieben. Durch den Zorn der Götter kamen nun alle Männer und alle Knaben von Wonosekar um, sodass die Männer von Masangan nur noch Frauen und Mädchen antrafen.

Diese verteilten sie nun unter sich, und seit jener Zeit sagen die Frauen der Tĕnggĕresen nur "Ingsun" und die Männer wie früher "Reang".

Aber in dem Dorfe Wonokitri, wo heut-zu-Tage alte Sitte noch am meisten gepflegt wird, hört man für "ich" aus Weibermund nur "Aku"; warum sie nicht "ingsun" sagen kann Niemand erklären.

Die Bewohner dieses Dorfes sind auch gemischter Abstammung, denn ihre Vorväter kamen aus Danglu itu und Losari (verschwundene Dörfer, deren Stätten aber noch bekannt sind), während ihre Vormütter von den gefangenen Inselbewohnern abstamıten.

\section{Die grosse Schlange.}

\section{Wie der Gute belohnt und der Schlechte bestraft wird.}

Als noch wenige Menschen im Gebirge wohuten lebte dort ein Mann, Kjahi Kures nnd seine Frau Njahi Kures; sie ernährten sich durch den Verkauf von Brandholz, das sie den Bewohnern der Küste lieferten. Eines Tages traf Kjahi Kures im Walde einen Dewa, der die Gestalt einer grossen Schlange hatte, und er erschrack so heftig, dass er bewustlos zur Erde sank. Aber die Schlange sprach ihn an: "Bist du ein Mensch oder ein Waldgeist, warum kommst du jeden Tag in den Wald; wenn du ein Mensch bist so werde wach, ich will dich etwas fragen." Bald erwachte Kjahi 
Kures und antwortete: "Ja, Gusti, dein Knecht ist ein Mensch " Wieder frug die Schlange: "Was machst du jeden Tag im Walde?" Und Kjahi Kures antwortete: "Ja, Gusti, ich muss alle Tage Holz holen um es zu verkaufen und von dem Ertrage zu leben." Da sagte die Schlange: "Ja, das darfst du auch thun, aber von dem Gelde, welches das Holz dir einbringt, musst du die Hälfte verwenden um Milch für mich zu kaufen, die andere Hälfte kannst die deiner Frau für ihren Haushalt geben. Vierzig Tage lang sollst du das thun, und am vierzigsten Tage sollst du dich neben die Spitze meines Schwanzes stellen." Kjahi Kures gehorchte und erwartungsvoll stand er am 40 $0^{\text {sten }}$ Tage neben dem Schwanz der Schlange. Da sah er Geld und goldenen Schmuck aus dem Schwanze rollen und die Schlange sagte: "Kjahi Kures, das ist für Dich, aber kein Mensch und auch kein Thier darf diese Geschenke sehen, auch nicht dein Sohn "Bambang dursilå", denn sein Karakter ist schlecht"

Diese Geschenke brachten Kjahi Kures vieles Glück, er wurde sehr reich und sein Sohn wurde lüstren. nach diesem Reichthum und frug seinen Vater: "Wie bist du so reich geworden? Hilf mir um Handel zu treiben, damit auch ich reich werde." Da der Vater nicht leugnen konnte dass er reich sei, so gab er dem Sohne vierhundert Gulden obgleich er seinen schlechten Karakter kannte. Von dem Gelde kaufte der Sohn bei einem Grosshändler in der Ebene "Trassi" '. Aber da er ein schlechter Mensch war, so verlor er beim Spiel wieder alles was er beim Verkauf erhielt. Da kehrte er zu seinem Vater zurück und als dieser ihn frug ob er mit Gewinn oder nit Verlust Handel getrieben habe, antwortete er: "Ich war unglücklich, ich kaufte Trassi, der von aussen wie schöner Trassi aussah, aber im Inueren was er faul und schmutzig, darum musste ich alles wegwerfen. Ich bitte dich mir wieder zu helfen."

Noch einmal gab der Vater ihm vierhundert Gulden. Auch diese Sunme verlor er beim Spiel.

Da kan er wieder in seines Vaters Haus und als dieser frug ob er mit Vorteil oder Verlust Handel getrieben habe, antwortete er: "Ich war wieder unglücklich, denn ich kaufte Klappa (Kokosnüsse), von aussen waren sie schön, von ihnen faul; ich musste sie wegwerfen."

1 Kleine Fische und Garneelen gesalzen, halb getrocknet, feingestossen und zu Kuchen gebildet. Diese mischt man wie Gewürze zu den Speisen. 
Da sagte der Vater: "Es ist besser, mein Sohn, wenn du zu Hause bleibst." Einige Zeit blieb der Sohn nun auch in der elterlichen Wohnung, aber dann regte sich wieder Neugier und Habsucht in ihm und er sagte zu seinem Vater: "Sage mir woher du deinen Reichtum hast oder ich töte dich." Da wurde der Vater traurig und bang und er erzählte dem Sohne sein Erlebnis mit der Schlange, das er hätte verschweigen sollen. Sowie der Sohn die Geschichte gehört hatte entschloss er sich auch Milch für die Schlange zu kaufen und ihr zu bringen, aber da er böse war wollte er die Schlange töten um sich des Geldes und Goldes in ihrem Leibe zu bemächtigen. Er ging in den Wald; drei Tage lang wartete der Vater und als der Sohn noch nicht zurück kam ging er hinaus in den Wald um ihn zu suchen, aber er fand nur seine Leiche; die Schlange hatte ihn getötet.

\section{Wie das Sandmeer entstand und warum der Reis nicht im Reisblock gestampft wird.}

Die Tĕnggĕresen stampften ihren Reis in einer Kuhhaut, ganz wie sie die Kaffeebohnen von der Fruchthülle befreien, also nicht in einem Reisblock (lumpang, lěsung). Damit hat es folgendes Bewandtnis. Kresno war König von Indoro Wati, aber sein Ruhm wurde verdunkelt durch den von Seno, Sohn des Pandu Dewo Noto. Denn Seno kannte einen Ngelmu oder Zauberspruch "BandongBondo-Woso" den Kombo Jono ihm gelehrt hatte. Diesem Zauberspruch dankte er wunderbare Kraft, die noch dadurch erhöht wurde, dass er ein Öl besass, ein Erbstück seines Grossvaters Abioso, welches ihn gefürchtet und unverwundbar machte.

Kresno ersann darum eine List um Seno unschädlich zu machen. Er bat ihn ihm seine wunderbare Kraft dadurch zu zeigen, dass er in einer Nacht vor dem Aufgang der Sonne eine solche Vertiefung grabe, dass sich ein grosses Meer darin bilden köune; die Belohnung für diese Arbeit solle eine seiner Töchter sein. Seno im Bewusstsein seiner wunderbaren Kraft, nahm den Auftrag an, und sowie die letsten Strahlen der untergehenden Sonne verschwunden waren, machte er sich an die Arbeit. Mit einem grossen ausgehölten Felsen schöpfte er die Erde um den Bromokrater weg und bildete um diesen ein breites, tiefes Ringthal das heutige Sandmeer. Gegen Mitternacht war die Arbeit fast fertig, nur an einer Seite war der Bromo noch nicht ganz umgraben. Da bemerkte 
Kresno dass Seno's Kraft doch noch weit grösser sei als er geglaubt, denn er hatte gehofft dass Seno sich lächerlich machen würde, weil er eine unmögliche Arbeit auf sich genommen habe. Jetzt musste er aber einsehen dass Seno's Name bald in der ganzen Welt als der des Mächtigsten auf Erden gefeiert werden würde.

Darum ersann er eine neue List; er liess die ganze Bevölkerung aus dem Schlaf wecken und hiess alle sofort Reis stampfen und die Hähne aus den Häusern treiben. Als Seno das Reisstampfen hörte und das Krähen der Hähne, da glaubte er dass der Morgen bereits angebrochen sei, vor er seine Arbeit vollendet habe. Beschämt warf er den Schöpfer weg, der noch heute in dem Sandmeer zu sehen ist wo er den Berg Batok bildete, verfluchte Kresno und den Reisblock als Ursache seines Unglücks und verschwand. Darum wagen es die Tĕnggĕresen nicht Reis im Reisblock zu stampfen. Von dieser Erzählung kennt man eine etwas andere Form, der Reisblock wird darin nicht genannt, nur die zu früh geweekten Hähne verkünden den Morgen vor die Arbeit beendet ist, welche nur unternommen wurde um die sehöne Königstochter zu gewinnen.

\section{Die Nymphe Bidolari-Navang-Wulan.}

Warum der Mann nicht den Deckel ron dem Korle (kukusan) nehmen darf, worin der Reis gekocht wird.

Es lebte in alter Zeit ein heiliger Mann: Guru Sunan-Bonang genannt, der durch seine Wunderthaten in den Geruch der Heiligkeit gekommen und dadureh grossen Einfluss erlangt hatte. Aber die Absonderung, in der er lebte, sein Fasten und Beten hatten doch nicht ganz die thierischen Triebe in ihm ertötet. Denn ein Weib, das gleichen Nimbus der Heiligkeit umgab und die er darum hänfig besuchte um sich mit ihr geistlich zu üben, wurde sehwanger und gebar einen Sohn. Um nun den Lästerzungen, die schon oft diese Zusammenkünfte bespöttelt hatten, nicht recht zu geben, entführte Guru Sunan Bonang dieses Kind und legte es heimlich anf das Grab eines gewissen Kjahi Gede, der unlängst gestorben war und dessen trostlose Witwe das Grab noch täglich besuehte. So fand die Witwe das Kind, erbarnte sich über dasselbe und sehwur bei den Mahnen des verstorbenen Gatten dieses Kind als ihr eigenes zu erziehen. Der Knabe erhielt den Namen des verstorbenen Mannes: Djoko-Tarup-Anom, wurde mit Sorgfalt 6e Volgr. IX. 
erzogen und wurde ein tüchtiger Jäger, der seine Mutter ernähren konnte.

Eines Tages als Djoko Tarup wieder im Walde umherstreifte hörte er plötzlich viele Stimmen reden, die ihn durch Wohllaut fesselten. Die Neugierde trieb ihn an, sich geräuschlos dem Orte zu näheru, von woher die Stimmen kamen. Mitten im dichten Gebüsch sah er plötzlich den Spiegel eines klaren Teiches schimmern, in dem zwölf schöne Jungfrauen spielten und badeten. Eine überstrahlte alle andere durch Schönheit, und ganz wie sein Vater konnte Djogo Tarup körperlichen Reizen nich widerstehen. Daher stahl er die Kleider dieser Nymphe und verbarg sie sorgfältig, denn er hatte bemerkt, dass uur an den Kleidern Flügel waren, die Nymphen also ohne diese nicht entfliehen konnten. Als die Nymphen nun des Badens genug hatten, stiegen die andern in die Wolken empor, während die unglückliche Bidodari-nawangwulan, deren Kleid nirgends zu finden war, allein beim Teiche zurück blieb, in Thränen aufgelöst.

Da näherte sich Djoko und versprach ihr die Kleider zurück zu geben wenn sie ihm einige Zeit als sein Weib angehören wolle. Die Nymphe wollte ihn zwar gerne als Bruder, als Freund annehmen, ihn als Retter lieben, aber nicht als Mann, doch musste sie schliesslich', zugeben, und Djoko Tarup bedeckte sie mit seinen Kleidern und brachte sie in seine Wohnung zu seiner Mutter, wo sie sehr freundlich aufgenommen wurde. Aber Djoko Tarup gab ihr ihre Kleider nicht zurück wie oft sie auch darum bat, da er nicht ohne sie leben wollte.

Die Nymphe wurde Njahi Gede des umliegenden Landes nach dem Tode der Schwiegermutter und gebar eine Tochter: NawangSeh. Sie hatte sich ganz in die Umstände eines gewöhnlichen Menschenlebens gefügt.

Eines Tages kochte sie den Reis, als sie plötzlich daran dachte dass sie die Kleider ihres Kindes noch nicht gewaschen habe, darum bat sie [ihren Mann auf deu Reis zu achten, aber unter keiren Umständen den Deckel (kĕkĕp) vom Korbe (Kukusan) zu lüften. Aber die Neugierde wirkte zo stark auf ihn ein, denn schon seit Jahren stand er vor dem Rätsel dass der Padi (Reis) in seinem Hause nicht abnahm, obgleich er, seit die Nymphe sein Weib geworden war, nie neuen Vorrat gekauft hatte. Die Lösung des Rätsels glaubte $e_{j}^{\prime}$ in dem Korbe zu finden. Er hob also den Deckel auffund sah in demselben nur einen einzigen Padihalm liegen. 
Kaum hatte er den Korb wieder geschlossen als seine Frau hereintrat, sie ging sofort zum Feuer und hob den Deckel vom Reiskorbe, da zeigte ihr der unversehrte Padihalm, der sonst in kurzer Zeit zu einer Menge Nasi (gekochter Reis) wurde, dass ihr Mann den Deckel anfgenommen habe.

Es half Djoko Tarup nichts dass er schwur den Deckel nicht geöffnet zu haben, denn der Reiskorb hatte seine Kraft für immer verloren und die arme Nawang-wulan war zum zweiten mal durch Djoko Tarup betrogen. Sie musste nun wie andere Frauen jeden Morgen und jeden Abend mit ihren Götterhänden den Reis für Mann und Kind stampfen.

Da nahm der Vorrat Padi auch schnell ab, gleichzeitig nahte aber auch die Zeit ihrer Erlösung. Als nur noch eine dünne Schicht den Boden der Reiskammer bedeckte sah Nawang-wulan auf dem Boden etwas glänzen, hastig zog sie es hervor und hielt ihr altes Flügelkleid in Händen, das Djoko Tarup dort verborgen hatte. Schnell zog sie es an und näherte sich, von himmlischem Glanze umstrahlt, zum letzten Male ihrem Manne.

Laut jammerte dieser und flehte ihn nicht zu verlassen aber die Nymphe antwortete: "Hoffnunglose Trauer soll dein Herz erfüllen, bis du durch ein Leben voll Busse und Reue wieder Ruhe findest und Vergebung für deine schändliche Wollust, deinen Betrug, deinen Ungehorsam. Sorge für meine Tochter, und wenn diese durch ihr Weinen dich an deine Sünden erinnert, bringe sie dann hinaus in's Feld, lege sie in einen Gubuk (kleines Wachthaus in den Feldern), gieb mir ein Zeichen durch ein brennendes Bündel Reisstroh und ich werde herbeieilen um den Hunger des Kindes zu stillen". Sie verschwand, und seit jener Zeit darf der Mann nicht den Deckel vom Reiskorbe heben.

\section{Der Opfertod von Kjahi Kusumo. W arum die Tënggěresen dem Bromo Opfer bringen.}

Ich habe diese schönste der Tĕnggĕrsagen früher herausgegeben ${ }^{1}$ und will hier nur hinzufügen, dass sie durch van Herwerden, der sie Anfang dieses Jahrhunderts aufzeichnete (1830) etwas anders erzählt wird. Erstens mit anderen Namen, das ist wohl das unwichtigste, er scheint

1 Waarom de Tenggerezen offers brengen aan den Bromo. De legende van Kjahi Koesoemo. Tijdschrift voor Ind. Taal-, Land- en Volkenkunde, deel XXXIX. 1896. 
die Namen einer anderen Sage entnommen zu haben. Zweitens werden hier alle fünfundzwanzig Kinder dem Bromo geopfert, aber passiv als noch unbewusste Kinder; dies ist entschieden unrichtig denn schon in der ältesten uns bekannten Form (1785) wird nur der jüngste Sohn dem Bromo geweiht. Hauptsache ist in jeder Gestaltung, dass der Tod eines Menschen, dem Krater des Bromo geopfert, dem Volke Segen brachte (reiche Ernten, Fruchtbarkeit u.s. w.). Dieses Opfer war das erste, das dem Bromo gebracht wurde, es wird nun jährlich beim Bromofeste in anderer Gestaltung wiederholt. Ich will hier die älteste Form in extenso geben, besonders auch weil sie dort mit einer anderen Sage verknüpft ist, die uns erzählt, woher der Tĕnggĕrrese die roten und weissen Zwiebeln erhielt, die in früherer Zeit, als die europäischen Gemüse noch nicht eingeführt worden waren, die wichtigsten Handelsartikel des Gebirges bildeten.

Putro und Putri waren Bruder und Schwester, Kinder eines heidnischen Fürsten in Bantam; da sie bei ihren Geschwistern nicht in Ansehen standen, verliessen sie mit einem kleinen Gefolge den Hof und die Heimat und suchten einen anderen Wohnsitz, der ihnen gefiele, und wo sie ganz frei leben könnten. Eine solche Gegend war auf Java nicht leicht gefunden und so zogen sie immer weiter bis zum Osten der Insel, wo sie sich endlich im Tĕnggĕrgebirge nieder liessen (sieh oben unter Geschichte).

Putro wurde das Haupt der neuen Kolonie und nannte sich Kjahi Dadap pĕtak (putih). Seine Frau gebar ihm fünf und zwanzig Kinder und auch sein Volk vermehrte sich sehr schnell. Die Folge war, dass sie in den Wäldern nicht mehr genug Nahrung fanden und grosse Not unter dem jungen Volke herrschte. Am meisten litt Kjahi Dadap pĕtak unter dieser Not, denn er liebte sein Volk wie seine Familie. Darum rief er das Volk zusammen, und in dessen Mitte tretend, that er folgendes Gelöbnis: Ich will dem Bromo eins meiner Kinder opfern wenn er soviel Segen giebt, dass wir alle genug Nahrung finden. (Hier erinnert der Bromo in seiner vernichtenden und dann wieder Segen bringenden Kraft sehr an Sjiwa). Bis dahin hatten die Tĕnggĕrezen nur von Kräutern und Wurzeln und einer Art Hirse gelebt, die sie djawa oderdjewawut nannten, die aber nur noch auf den weit abgelegenen Bergen wuchs ${ }^{1}$. Beim Hirse-suchen hatten sie denn auch den

1 Viele leiten den Namen der Insel Java von dieser Hirse her, Pulu Djawa oder Java würde also Hirseninsel bedeuten. 
Smeru (Mahameru) entdeckt, und gesehen dass dort Menschen wohnten. Zu diesen zog Kjahi dadap pĕtak; er fand dort einen Mann Sangjang ${ }^{1}$ Wiseso genannt und seine Frau Dewi Supurbo, beide lebten wie Heilige und wurden Tåpås genannt und vermochten viel bei den Göttern durch ihre Fürsprache. Kjahi Dadap pĕtak baf sie um Hülfe, die ihm von den Tåpås zugesagt wurde. Nach einigen Tagen teilte der Mann ihm mit, dass seine Frau während der Nacht im Schlafe zwei Knollen in ihre Hand empfangen habe, die eine sei rot die andere weiss. In derselben Nacht habe er im Traume eine Stimme aus der Luft gehört (Suwara-awang-awang), die ihm befohlen habe: "Die Knollen, welche deine Frau in ihre Hand empfing sollst du Bawang abang (rothe Zwiebeln) und Bawang putih (weisse Zwiebeln) nennen, und sie Kjahi Dadap pĕtak geben, der soll sie in dem Gebirge pflanzen und er und sein Volk werden durch diese Zwiebeln zu Wohlstand gelangen. Sage ihm weiter dass sie alles pflanzen dürfen was sie wünschen, nur keinen Padi (Reis), denn wenn sie diesen pflanzen werden alle, sammt ihren Nachkommen, unglücklich werden.

Kjahi Dadap pĕtak gehorchte, und schon nach zwei Jahren brachten die Zwiebeln dem Volke Wohlstand und Nahrung durch den Verkauf. Da gedachte Kjahi Dadap pĕtak seines Gelübnisses und in Gegenwart des ganzen Volkes warf er seinen jüngsten Sohn in den Krater als ein Dankopfer für die Hülfe der Götter. Das ist das einzige Menschenopfer, das je dem Bromo gebracht wurde, später beim Bromofest opferte man nur Thiere und Früchte. Der neueren Fassung 'nach, waren alle fünf und zwanzig Kinder dem Bromo versprochen, aber opferte sich nur der jüngste, der fünf und zwanzigste, freiwillig den Göttern.

\section{Bau und Einrichtung der Wohnung.}

Die Wände des Hauses werden aus aufrechtstehenden Brettern gebildet, welche mit Rottanschlingen an einander befestigt werden, der Aermere wählt Baumfarnstämme oder gespaltene, plattgeschlagene Stücke Bambu. Zuweilen werden die Häuser an der Aussenseite noch mit langem Grase (alang-alang) bekleidet, und meist findet man an der inneren Seite noch eine Schicht aus

1 Sangjang oder Sanghjang ganz wie Dewi oder Dewa ist ein allgemeiner Name für göttliche Wesen, Tåpå für fromme Einsiedler. 
dünnen geflochtenen Pambustreifen. So schützt man das Innere vor dem kalten Bergwind. Das Dach wird auch aus Alang-Alang gefertigt, doch den untern Teil des Daches an der linken Seite bedeckt man mit gespaltenen Bambu (Klakah), die so einander gelegt werden, so dass der Regen nicht hereindringen kann; diese Bambu kann man leicht aus einander schieben und so das dunkele Innere des Hauses erhellen. Die Hausthüre findet man stets an der einen Längsseite des Hauses und zwar an der linken Ecke, die dem Bromo zugekehrt ist, der Eintritt wird durch ein kleines Dach geschützt (pĕnirat früher trappat), unter welchen man auch die Arbeiten verrichtet, für die es im Hause zu dunkel ist. An der der Thüre entgegen gesetzten, schmalen, rechten Seite des Hauses ist ein kleines Fenster angebracht. Der Innenraum zeigt die folgende Einteilung: an der linken schmalen Wand werden die Akkerbaugeräthe, der Maisblock u. s. w. verwahrt; in der Höhe sieht man ein Gerüst oder einen Soller (pågå) auf dem allerlei Dinge verwahrt werden. Dort legt man auch die Opferspenden bei Festlichkeiten nieder, und dann heisst der Soller Sanggar Pamalengang. Den grössten Teil der beiden langen Seiten nehmen niedrige, breite Bänke (ambèn) ein. Auf diese Bänke, weiter nach rechts, folgen kleine Kammern (Kobong), die eigentlich nur, durch Zwischenwände abgetrennte, Teile der langen Bänke sind. Eine Kammer ist für den Hausherrn und seine Frau und die anderen für die verheirateten Töchter, meist hängen Gardinen oder Kleiderfetzen vor den Thüren dieser Kammern. Im Raume zwischen den beiderseitigen Kammern brennt das Heerdfeuer zwischen grossen durch Mörtel verbundenen Steinen (pawon). Um den Heerd stehen niedrige Bänke. Die letzte (ganz offene) der Kammern an der Vorderseite birgt das Küchengeschirr. Da viele Kammern in einem Hause sind und der Raum bei der Thüre, wo zu beiden Seiten die langen Bänke stehen, stets sehr gross ist, um alle Gäste bei Festlichkeiteu empfangen zu können, so sind die Häuser immer sehr lang. Die Häuser liegen auf kleinen Terrassen über einander, in den meisten Dörfern ist der Raummangel auf den scharfen Bergrippen so gross, dass die Häuser gar keinen Hof oder Garten haben. Die Thüre wird durch ein Querholz an der inneren Seite geschlossen, kann aber von aussen durch ein an das Querholz befestigtes Tau von Rottan geöffnet werden. Kinder und Gäste schlafen auf den langen Bänken. 


\section{Allgemeine Sitten.}

Wenn man die älteren Mitteilungen über dieses Volk liest, dann erinneren sie lebhaft an ein idyllisches Arkadien. Mord, Diebstal, Streit, Ehebruch waren fast unbekannt; die Tĕnggerresen waren scheu aber aufrichtig und nicht eifersüchtig. Ehescheidungen waren sehr selten. Der Commandant von Pasuruan schrieb schon 1785, dass während der dreizehn Jahre seiner Regierung weder Todschlag noch Diebstal vorgekommen sei. Jünglinge und Jungfrauen gingen frei mit einander um, schliefen häufig auf der ambèn nebeneinander, und doch kam Ehebruch nicht vor, ebensowenig Polygamie. Die Gäste wurden gerne empfangen, man liess sie ohne Angst neben den Mädchen schlafen, wenn es Tĕnggĕresen waren; von den Bewohnern der Ebene erfuhren sie bald genug, dass man ihnen nicht vertrauen könne. Die Tänzerinnen (ronggengs) wurden früher denn auch tief verachte $\iota_{\iota}^{\iota}$ und in den Bergen nicht geduldet (v. Herwerden). Dem Europäer begegneten sie mit grosser Ehrfurcht. Sie stritten nie über den Nachlass der Verstorbenen und bei kleinen Uneinigkeiten unterwarfen sich alle dem Richterspruch des Dukuns. Man heiratete erst spät, der Jüngling nicht vor dem $20^{\text {sten }}$ Lebensjahre, das Mädchen nicht vor ihrem $16^{\text {ten }}$, und Donis weiss uns mitzuteilen dass die Männer lieber eine Witwe als eine Jungfrau heirateten. Geschlechtskrankheiten waren ganz unbekannt; sie fehlen auch heute noch dort, wo keine Europäer wohnen. Trunksucht und Opiumrauchen wurden nie beobachtet.

Die von der Regierung über sie angestellten Oberhäupter, (Regenten, Demangs, Petinggis u. s. w.) behandelten sie ohne Scheu, wie ein älteres Familiënglied mit Ehrfurcht und Liebe, und diese Beambten zeigten gleiches Entgegenkommen.

Also ganz paradisisch werden uns die älteren Zustände geschildert. Ich bin überzeugt dass Vieles nicht übertrieben war. Noch heute sind Mord und Diebstal sehr seltene Vorkommnisse, wenn man die Thaten der zugezogenen Bevölkerung nicht in Rechnung bringt. Streit und Eifersucht sind dem Volke noch jetzt fremd und gerne unterwirft man sich noch heute freiwillig den Richtersprüchen des Dukuns, während man den eigentlichen Beambten aus dem Wege geht. Der Tĕnggĕrese ist bange vor Streit, er liebt die Ruhe und erträgt vieles Unrecht bevor er sich entschliesst zu klagen. 
Die zugezogenen Maduresen und Javanen fügen sich meist nach diesem Volkskarakter, sodass auch diese selten stehlen, was der Tĕnggĕrese dem guten Einfluss der Schutzgeister seines Dorfes zuschreibt. Nur in einer Hinsicht glaube ich war die Beschreibung übertrieben, nämlich in Bezug auf die geschlechtlichen Verhältnisse. Die schon von Domis erwähnte Thatsache, dass man lieber eine Witwe als eine Jungfrau heiratete, deutet an, dass man Jungfraülichkeit nicht zu schätzen wusste. Schätzte man sie aber nicht, dann war für die Mädchen auch kaum ein Grund vorhanden sie zu schützen und man kann doch nicht annehmen, dass der Geschlechtstrieb erst erwachte wenn die Heirat in Aussicht war. Das dem Volke so charakteristische Fehlen der Eifersucht erregte wohl den Gedanken, dass ihr jeder Grund dazu durch allgemeine Keuschheit fehle. Die Wahrheit ist, dass in der Ehe Mann und Weib einander treu blieben auch "an Scheidung" nicht gedacht wurde, aber vor der Ehe war manches erlaubt. Es schliefen die jungen Leute allerdings neben einander und waren sie oft allein zusammen auf dem Felde und im Walde; ein junger Man als Gast verlangt noch heute neben der Tochter des Hauses zu liegen und doch behaupten sie dass der Coitus nicht ausgeübt werde. Bei Controle wurde aber gefunden dass den Mädchen oft das Hymen fehlt, und doch wird eine vorehliche Schwangerschaft selten beobachtet, kommt sie doch vor, dann schreibt man sie dem Teufel zu. Wir müssen also annehmen dass die jungen Leute vor der Ehe geschlechtliche Befriedigung in einer gewissen Weise suchen, die die Befruchtung ausschliesst. Übrigens gilt dies heute nur noch für die abgelegenen Dörfer, in den anderen ist es dem Manne gleichgültig ob sein Weib mit einem anderen Manne verkehrt, wenn er es nur nicht sieht und ob er eine Jungfrau oder eine Deflorierte heiratet, ist ihm auch gleichyültig. Vor der Heirat findet auch regelmässig geschlechtlicher Verkehr statt und Niemand findet das anstössig. Auch kommt es jetst vor, dass man zeitweise die Frauen austauscht und dann wieder zurücknimmt.

Polygamie ist auch heute noch selten, Ehescheidungen kommen jetzt aber haüfiger vor. Auch ist das alte Gesetz, dass ein Mann sich nur zweimal scheiden lassen dürfe, fast vergessen. Spätes Heiraten und freie Wahl bei den jungen Leuten ist heute noch Sitte, die Eltern fügen sich ganz dem Wunsche der Kinder.

Den Ackerbau trieben sie und treiben sie noch heute ohne Vieh; 
das Hornvieh ${ }^{1}$ wird nur um sein Fleisch gehalten, die Pferde für den Transport; diese tragen die Lasten auf hölzernen Sätteln. Man bearbeitet den Boden mit dem Patjul (Hacke) und die Frau hilft dem Mann; letzterer sorgt allein für den Transport der Exportwaren nach dem Markte. Früher pflanzte man Mais, Zwiebeln und Djarak (Ricinus); heute auch alle Europäischen Gemüse. Die Hauptnahrung ist Mais, auch jetzt isst kaum 2 pCt. der Bevölkerung Reis, und dann auch nur zeitweise, besonders bei Festen; in manchen Dörfern sieht man nie Reis am häuslichen Heerd. Sie behaupten, dass Mais mehr Kraft gebe und länger den Hunger stille. Bei langen Märschen führen sie häufig aus Kĕtan (kleberiger Reis) und Mais gemischte Kuchen mit sich. Früher waren die Tĕnggĕresen tüchtige Jäger, heute ist das Wild selten geworden, doch essen sie noch gerne wilde Tauben, einige Eichhörnchen und Rehe (Kidang). Eine Jagd, die in ganz besonderer Weise getrieben wurde, war die des Banteng (Bibos banteng), der wilden Kuh. Der letzte Jäger, der sich mit dieser Jagd befasste, war Pa Sedeh, der Stifter der kleinen Dessa Ngadas. Er war der beste Führer im Gebirge, besonders für den Smeru nnd als guter Jäger war er auch entsprechend abergläubisch. Von seinen Zauberformeln weiss ich leider nichts mit zu theilen, er starb ehe ich in's Gebirge kam, aber wie er Bantengs jagte, das konnte man mir noch erzählen. Er ging stets allein in den Wald mit einem roten Lappen und einem grossen langen Messer (Axt). Mit dem roten Lappen reizte er den Banteng, bis er auf ihn losstürmte, dann sprang er schnell zur Seite, liess den Banteng vorbeistürmen, und mit blitzschnellem Schlage durchschnitt er ihm die Achillessehnen der Hinterbeine. Auf diese Weise soll er 70 Bantengs getötet haben.

Wirkliche Armut ist unbekannt und erwachsene Bettler sieht man nirgends. Feuer machte man früher (vor Einführung der Streichhölzer) durch schnelles aneinanderreiben von trockenem Bambu, oder von Klandingan-Holz (Albizzia montana) mit feinen Fasern zwischen den reibenden Flächen (usu-usu). Man benutzte (als man Lampen und Petroleum noch nicht kannte) kleine Lampen aus Thon (Templek), diese standen auf einem hölzernen Fuss (Djodog oder Planduk gleich dem Adjuq-adjuq der Javanen), der in die Erde des Hausflurs befestigt wurde. In den Lampen brannte man

1 Jetzt findet man auch viele Ziegen, die auch nur als Schlachtvieh gezogen werden; auch spannt man, seit neue Wege angelegt wurden, die Kühe vor die hölzernen Karren. 
Djarak- (Ricinus communis) Öl, das man selbst aus den Früchten bereitete. Diese Lampen konnten sie nicht selbst an fertigen, sie kauften dieselben, sowie alle Geschirre und Eisenwaren in der Ebene. Als Hohlmass kannten sie nur geflochtene Körbe bestimmter Grösse und als Längenmass das dĕpå (Klafterweite).

Als djimats (Reliquien oder Amulette) kennt man nur alte chinesische Münzen und einige besitzen einen Kris (Dolch). Die Männer tragen eine kurze Hose (Katok) und eine breite Leibbiude (Sabuk), früher einen blau und weiss gewürfelten Sarung ${ }^{1}$, den sie wie einen Mantel um den Oberleib hingen, dass Brust und Schultern bedeckt waren, jetzt tragen sie meist auch Jacken. Im. Gürtel, auf dem Rücken tragen sie immer ein langes grades Messer in hölzerner Scheide, welches sie bei allen Arbeiten, besonders beim Holz-hacken, benutzen. Früher scheinen sie Kopftücher gar nicht gebraucht zu haben, auch heute noch gehen viele mit entblösstem Kopf und kurz geschnittenen Haaren umher, wer ein Kopftuch benutzt, dreht es nur lose um den Kopf. Hüte kaufen sie jetzt von den Bewohnern der Ebene.

Die Weiber unterschieden und unterscheiden sich in der Kleidung nicht von andern Javanerinnen.

Das Hornvieh, dessen Glocken an die Schweiz erinneren, und auch die nicht benutzten Pferde liefen früher frei umher, die Kühe wurden, wenn man sie schlachten wollte, erst mit Mühe eingefangen, jetzt findet man Pferde und Kühe zwar meist in den Ställen, oder auf den Weideplätzen, von wo man sie Abends (wohl wegen der Gemüsepflanzungen) heimtreibt, aber viele streifen noch frei umher auf den höheren Gipfeln, wo keine Pflanzungen sind. Wilde Schweine wurden früher viel gejagt und verzehrt, heute nur noch von den Bewohnern einiger Dörfer, denn die meisten Tĕnggĕresen fürchten sich vor dem Spott der Javanen.

Fisch, auch getrockneter, ist ein seltner Leckerbissen; im allgemeinen ist die Nahrung sehr einfach, es fehlen fast alle Gewürze, der Javane liebt es denn auch nicht am Tische der Tĕnggĕresen zu essen.

Die Musik lieben sie sehr, sie haben aber keine eignen Musikinstrumente; bei vielen Wohlhabenden (besonders in der Resident-

1 Für die Badoejs in West Java sind auch blau und weiss die einzigen erlaubten Farben, aber diese sind nicht in Würfel sondern in Streifen auf den Sarungs verteilt. 
schaft Probolinggo), findet man einen Gamelan; nie fehlt dieser im Hause des Priesters.

Standesunderschiede kennen sie nicht, der ärmste Mann darf die Tochter des Reichsten zum Weibe begehren. Die Unterschiede zwischen Kromo und Ngoko (Hohe und Niedere Sprache) sind ihnen denn auch fast unbekannt, sie irren sioh fortwährend und der kleine Mann spricht öfter von sich selbst mit Kromo oder Kromo inggil (Hoffsprache) Worten; nach und nach lernt er allerảings die Unterschiede durch die Javanischen Beamten. Der unverfälschte Tĕnggĕrese wird auch den höchsten Beambten, den Regenten, wie seinen Vater mit "bapak" (Vater) und Ngoko-Worten anreden, auch den Europäer ohne Scheu ausfragen. Die Freimüthigkeit der Bergbewohner schlägt heut zu Tage, durch den vielen Umgang mit Turisten, allerdings leicht in Freiheit um. Der $\stackrel{a}{a}$ Klang der Javanischen Sprache wird beim Tĕnggĕresen wie beim Sundanesen $a$.

Die Irren (meist Cretins) werden freundlich behandelt; Krankheiten ${ }^{*}$ sind selten, ein hohes Alter erreichen sehr viele.

Wenn man ein Haus baut, giebt man ein Fest sowie das Gerüst des Daches fertig ist, man schmückt das Gerüst mit kleinen Fahnen und Zweigen, auch wird bei diesem Fest (Schmauserei mit einleitendem Gebet) ein $\mathrm{Ei}$ in den Boden genau unter der Mitte des Daches eingegraben. Erntefeste giebt man nicht.

\section{Mann und Weib.}

a. Hochzeit. In den Hochzeits Gebräuchen hat sich Manches geändert, heute sind sie weit einfacher als früher, aber auch in alter Zeit wurde in so fern Unterschied zwischen Reichen und Armen gemacht, dass bei ersteren das Fest grösser und complicierter war. Van Herwerden und Domis haben in den $30^{\text {er }}$ Jahren je eine Hochzeit mitgemacht, die nicht nur wegen der vornehmen Besucher, sondern auch weil die von van Herwerden besuchte Hochzeit im Hause des Häuptlings stattfand, weit glanzvoller waren als man sie jetzt sieht. Mit einigen Worten will ich daher erst die einfache Form der heutigen Eheschliessung mitteilen und dann die Beschreibungen von v. Herwerden und Domis zu einheitlicher Darstellung vereinigen. Die jungen Leute sind hier ganz frei in ihrer Wahl, meist haben sie die prima Nox bereits genossen bevor sie den Eltern mitteilen, dass sie einen Ehebund schliessen wollen. Kennt die Mutter den Wunsch ihres Sohnes so 
wird sie sich zur Mutter des Mädchens begeben, um diese für die Heirat zu gewinnen. Alles geht dabei ohne Feierlichkeiten her bis zum Tage, an dem man sich zum Priester begiebt, um die Ehe schliessen zu lassen. Es bestimmt auch der Priester den Hochzeitstag, damit ein dazu geeigneter glückbringender gewählt werde. Die Ehe wird jetzt stets im Hause des Priesters geschlossen und nicht im Hause der Eltern. Die jungen Leute werden von den Vätern oder einem Wali (Vormund) oder sonst von einem Familiengliede zum Priester gebracht. Der Wali teilt dem Dukun mit, dass das Paar heiraten wolle und dass der Bräutigam der Braut 1000 Keteng bezahlen werde (Keteng $=\frac{1}{2}$ Cent). Dann frägt der Priester den Bräutigam ob er die Tochter seines Vaters (der Schwiegervater werd hier bereits Vater genannt) heiraten wolle, sie als sein Weib nach der Sitte behandelen, kurz hält ihm mit einigen Worten seine Pflichten vor. Er antwortet dann: "Ja ich will sie heiraten, dass sie meinen Haushalt führe und mir bei der Arbeit helfe." Dann wünseht der Dukun ihm Glück und Wohlstand zu. Eine unverständliche Eidesformel wird ihnen dann vorgesagt, die sie beide wiederholen müssen, worauf die Ehe mit einer neuen Zauberformel eingesegnet wird. Der Priester nimmt dann noch die Geschenke in Empfang, die von den Brautleuten mitgebracht wurden. Diese Geschenke (Sandingan) bestanden früher aus Speisen und Geld, jetzt nur noch aus Geld und zwar stets zwei Gulden. Auch diese Geschenke werden mit einem Gebet angenommen.

Damit ist die Ehe geschlossen und folgt ein gewöhnlicher Schmaus in dem Hause des Vaters der Braut oder dem des Bräutigams oder in beiden, also dann ein doppeltes Fest. Das junge Paar zieht in's Haus der Eltern der Braut, wo ihr ein eigenes Zimmerchen als Schlafstelle angewiesen wird, der junge Ehemaun ist jetzt nur noch der Sohn seines Schwiegervaters. Der Hochzeitsschmaus regelt sich nach dem Wohlstand der Eltern, häufig wird dabei eine Kuh oder ein. Stier geschlachtet.

Das Thier wird (auch bei andern Festen) an einen Pfahl gebunden und Tage lang, bevor es geschlachtet wird, gereizt und gequältt ${ }^{1}$, je heftiger das Thier sich wehrt, um sich schlägt, brüllt u. s. w. desto grösser ist die Freude. Häufig sieht man auch dass

1 Vermutlich geschieht dies um das Fleisch weicher, zarter, schmackhafter zu machen, aus gleichem Grunde lässt man die Hühner mit abgeschnittenem Kopf herumlaufen. In den Tropen kann man ja nur frisch geschlachtetes essen, also das Fleisch nicht hängen lassen. 
der Bräutigam einen Dolch in den Hinterteil des noch lebenden Thieres sticht; damit hat es folgende Bewandnis. Wenn ein Kind schwer krank ist, gelobt man häufig dem Bromo ein Opfer zu bringen, oder der Vater verspricht, wenn das Kind am Leben bleibt, eine Kuh zum Hochzeitsschmaus zu geben. Diese Kuh erhält dann den ersten Stich von dem Bräutigam in seinem eignen Namen, wenn er selbst durch das Gelöbnis genas, oder in dem seiner Braut wenn für diese eine Kuh versprochen worden war. In andern Dörfern geschieht der Stich nicht wirklich, sondern es wird nur ein Dolch auf einem mit Blumen geschmückten Teller dem Thiere gezeigt. Jedenfalls, ehe man das Thier schlachtet, teilt man diesem in einer kurzen Ansprache mit, dass er geschlachtet werden solle und zwar aus diesem oder jenem Grunde.

Betrachten wir jetzt die alten Hochzeitsgebräuche, welche sich zum Teil noch in abgelegnen Dörfern (besonders in Ngadisari) erhalten haben. Das Jawort der Braut war früher ein Sirihblatt mit zubehören (Betel), zum Kauen dem Jüngling dargereicht. Dann folgte noch eine eigentliche Verlobungsfeier. Die Besan (Eltern der jungen Leute) bestimmten einen Tag, an dem die Verlobung der Familie mitgeteilt werden sollte. Die Angehörigen des Bräutigams versammelten sich an diesem Abend in dessen Wohnung und gingen dann in langem, unregelmässigem Zuge nach dem Hause des Brautvaters oder des Brautvormundes (Wali), wo die Familienglieder der Braut versammelt waren. Der Vater des Bräutigams machte dort den Wunsch des Sohnes bekannt, der Vater der Braut gab seine Zustimmung und teilte diese den Anwesenden förmlich mit, worauf man einander Glück zuwünschte und der Priester den Tag der Hochzeit bestimmte. Der Vater der Braut gab nun einen Schmaus, wobei die beiden Väter aus einer Schüssel assen, um zu zeigen dass sie in dieser Angelegenheit vollständig übereinstimmten. Geschenke erhielt Niemand weder die Braut noch ihre Eltern, ein Brautkauf fand also nicht statt.

Am Hochzeitstage begab sich der Bräutigam wieder zum Hause der Braut, dabei begleiteten ihn seine Verwandten und Freunde. Er war dabei mit Blumen geschmückt und sein ganzer Körper war Saffrangelb angestrichen (boreh-boreh) ${ }^{1}$, auf dem Kopfe trug er einen geschmückten Hut (Kuluk) oder verzierte Gold- oder Kupferplaten an den beiden Seiten des Gesichtes wie die Wajang-

1 Boreh-Boreh ist Puder aus gelber Erde mit feinem Reispulver und Moschus. 
figuren. Beim Hause der Braut angekommen musste er draussen warten während die Begleiter hineingingen. Dann wurde die Braut herausgebracht, auch diese war mit boreh-boreh beschmiert und mit Blumen geschmückt, sie trug Armbänder (Gelang-Bahu) und eine goldene dreireihige Halskette (Kalung-Susun-Tiga). Beide wurden nun im Dorfe herumgeführt, wobei ein Sonnenschirm (Pajung) über sie gehalten wurde, man machte dabei Musik, sang und lärmte. Die Braut wurde also nie getragen wie bei den Javanen ${ }^{1}$. Dann kehrte man in's Haus der Braut zurück, die Braut setzte sich in eins der Zimmerchen neben dem Heerde, das reich mit Blumen und buntem Papier ausgeschmückt war und allerlei Speisen enthielt; der Bräutigam setzte sich neben die Hausthüre auf die äusserste Ecke der langen Bank (Ambèn). Auf den langen Bänken zu beiden Seiten des Hauses sassen alle Gäste, die Frauen rechts, die Männer links und zwar nahmen die Familienglieder der Braut immer die dem Heerde zugekehrte Hälfte der Bank ein; die beiderseitigen Familienglieder blieben also getrennt. Zwischen den beiden Gruppen männlicher Familienglieder sass der Priester gegen die Wand des Hauses angedrückt (diese Verteilung der Gäste beobachtet man noch in Ngadisari).

Der Soller (hohes Gestell) beim Eingang (Sanggar) war wie ein Altar reich mit Zweigen und Blumen geschmückt, auf demselben lag ein Brett mit Töpfen, Kokosnüssen, Blumen, Früchten, Reis, Zucker, auf dem auch drei aus Blumen gefertigte Puppen standen, (gleich denen beim Todtenfest), an dem Soller hing eine kleine Leiter mit drei Sprossen. Alles was auf dem Sanggar lag war ein Geschenk an die Götter, welche wahrscheinlich durch die drei Puppen representiert wurden.

Der Gebrauch ist jetzt verschwunden. Der Gamelan stand früher auf einer der langen Bänken, heute am Eingang auf der Erde in der Nähe des Sanggar. Bei grossen Hochzeitsfesten sah man früher (zuweilen heute noch) eine Anzahl Puppen auf einer der Bänke (die der Frauen) sitzen, die die verstorbenen Häuptlinge und die Vorfahren des jungen Paares representierten. Vor diesen

1 Die Kleidung der Brautleute ist noch dieselbe wie früher, doch trägt man jetzt häufig die Braut umher, der Umzug geschieht in Tosari bei Tage, in Ngadisari nur Abends. Das Armband trägt die Braut am Oberarm, es ist kein geschlossener Ring, sondern eine Figur (Vogel, Pferdekopf u. s. w.), die mit Bändern am Arme befestigt wird. Die Hochzeitskleider sind Eigentum eines Verleihers und werden also nach der Hochzeit zurückgegeben 
lagen kleine Häufchen von Blumen, viele Früchte und zubereitete Speisen, auch ein Paar brennende Lampen standen vor den Puppen. Die Anzahl dieser Puppen sollte bei wohlhabenden Personen 44 sein (wahrscheinlich 42 wie beim Njewufest), bei Ärmeren sah man eine kleinere Anzahl.

Während man Speisen herumreichte wurde die Gesellschaft iu verschiedener Weise unterhalten. Auf der Bank der Männer, dem Dukun gegenüber, sassen zwei Bevollmächtigte, der eine der Braut und der andere des Bräutigams, es waren dies keine Familienglieder wie Domis behauptet, sondern in jeder Dessa fand man zwei solcher Männer, die bei jeder Hochzeit als Zeugen fungierten, da sie die einzigen waren, welche das lange Wechselgespräch, welches sie vorführen mussten, auswendig gelernt hatten.

Nach Domis führten sie ein Gespräch über die ehelichen Verpflichtungen, die sie einander vorhielten, dabei gelobend treu den Sitten und Vorschriften der Götter zu folgen. Das Gespräch endete damit dass sie einander Sirih anboten; hinter dem Bevollmächtigten der Braut sass der Vater der Braut und hinter dem des Bräutigams der Vater des Bräutigams. Die Väter bekräftigten jedes Gelöbnis durch ein monotones "ja" ${ }^{1}$.

Van Herwerden sah die Gäste andern Kurzweil treiben. Sie gaben einander Rätsel auf, die abwechselnd gelöst wurden. Die Richtigkeit der Lösung wurde von einem Rate beurteilt. Dieser Rat bestand aus den vier ältesten Männern der Gesellschaft, der erste war der Vorsitzende und nannte sich Kertidjojo, der zweite wurde Djaksa genannt und bestimmte die Busse, wenn die Lösung des Rätsels unrichtig war, den dritten hiess man Senopati, den vierten Kĕbajan. Die Strafe für unrichtige Antworten bestand meist darin dass man ein oder mehrere Schluck Sadjĕng (Arak) ${ }^{2}$ trinken musste, der in Kuhhörnern, deren Spitze man zu einem Trinkglase

1 Es gelang mir noch zwei alte Männer zu finden, die dieses Wechselgespräch noch auswendig kannten. Ich liess es durch meinen Javanischen Schreiber aufschreiben, und habe das Manuscript der „Bataviaasch Genootschap" übergeben.

${ }^{2}$ Nach Burer darf man den alten Trank der Tĕnggĕrezen nicht Arak (wie Domis) nennen, denn er hält keinen Alkohol. Sie trinken den Saft der Arenpalme (legèn-arèn) frisch aus dem Baume gezapft, also vor Gährung oder Alcoholbildung eingetreten ist, er ist also weder betäubend noch erregend (wie der Tuwak oder Tjokaq) sondern hat nur einen faden süssen Geschmack. Die Tĕnggĕrezen, die diesen Trank von weit her holen müssen, kochen ihn gleich nachdem er gewonnen wurde, und verhinderen dadurch die Gährung. 
umgebildet hatte, umhergereicht wurde ${ }^{1}$. Vielleicht wurde dieser Brauch bei der von Domis besuchten Hochzeit absichtlich übergangen, weil zwei hohe Beamte (Resident und Regent) dabei anwesend waren und man zu grosse Fröhlichkeit vermeiden wollte. Heutigen Tages trinkt der Tĕnggĕrese gerne Europäische Getränke.

Braut und Bräutigam namen an diesem Vergnügen keinen Anteil, sie blieben steif wie Holzpuppen sitzen. Weiter amüsierte man sich mit Tänzen (Tandak), es ist bemerkenswert, dass dabei die Tanzmädehen (Ronggengs, gleich Bajaderen oder Freudenmädchen) in diesem Gebirge nicht zugelassen wurden, man verachtete sie; jeder tanzte, der wollte, mit seinen Bekannten, wie bei Europäern; heute sieht man überall Tanzmädchen, nur in den Dörfern der Residentschaft Probolinggo werden sie noch nicht zugelassen. Bei sehr grossen Hochzeiten sah man früher auch das Stechspiel (Sodoran), das heute nur beim Karofest geübt wird und dort näher beschrieben werden wird. Die ersten Tänze geschahen in folgender Reihenfolge. Erst begab sich der Dukun im Tanzschritt nach dem mit Blumen geschmückten hohen Gestell (Sanggar), wobei er den Zodiakbecher mit Wasser gefüllt und den Blumenwedel in den Händen hatte. Dann tanzten die beiden Väter und setzten sich zu beiden Seiten des Dukuns vor dem Sanggar nieder, dann tanzten die beiden Mütter, die sich links und rechts neben ihre Männer niederliessen. Auf diese folgten alle jungen Mädehen und tanzten den Tanz "Antjak antjakan" 2, darauf wurden Braut und Bräutigam tanzend zusammengebracht (nach Domis durch die ältesten Verwandten ${ }^{3}$, nach v. Herwerden durch die jungen Mädchen). Alle Gäste sassen nun vor dem Sanggar (Altar), das junge Paar in der letzten Reihe, wobei sie einander die Hände reichten. Jetzt folgte ein langes Gebet des Priesters, wobei er das Wasser

1 Jedes Dorf besitzt solch ein Trinkgefäss, meist ein sehr altes. Es scheint dass man jetzt diese Rätsel nicht mehr bei Hochzeitsfesten aufgibt sondern beim Karofest (sieh dort).

2 Diesen Tanz hat man jetzt vergessen, man behauptet aber dass er nicht bloss durch Jungfrauen getanzt wurde sondern durch 4 Jünglinge und 4 Jungfrauen und zwar ausserhalb des Hauses.

3 In Ngadisari heute noch durch die ältesten Männer und Frauen. In Tosari ist es Sitte, dass die Brautleute, wenn der Bräutigam ein Jüngling ist, vor dem Hause des Priesters, wenn sie zur Eheschliessung dort hin komen, oder auch vor dem Hause der Braut, durch einige alte Männer und Frauen empfangen werden, die vor der Thüre des Hauses einen Tanz aufführen. 
aus dem Becher umhersprengte und alle Gäste ein Blatt mit Blumen in die Höhe hielten. Nach dem Gebet nahm der Priester einen irdenen mit Wasser gefüllten Topf voin Altar; dieses Wasser nannte man Banju-Parwato, das Wasser der Reinigung, in diesem lag ein Wedel aus Waringinblättern '. Mit diesem besprengte er dreimal Braut und Bräutigam und nachher die Angehörigen, dann setzte er den Topf wieder auf den Altar. Nun begab der Priester sich nach der andern Schmalseite des Hauses, verrichtete ein Gebet vor dem brennendeu Heerd, dann vor den aufgehäuften Speisen in dem Raume der Küchengeräthe (sieh oben Seite 102) und zum Schluss vor den in einer Reihe sitzenden Puppen.

Darauf kehrte er zum Altar zurück, gab dem jungen Paar und jedeın der Angehörigen etwas fein gemahlenen Reis in die rechte Hand, holte nun eine mit Wasser gefüllte Cocosuuss von dem Altar, in der drei kleine Röhren befestigt waren, aus denen er etwas Wasser in die Hände derselben Personen goss, die nun alles zum Munde führten. Nun brachte man grosse Schüsseln mit Reis und Früchten heran. Eine stellte man auf den Altar, neben diese ein Gefüss mit Weihrauch (Dupå) und unter fortwährendem Reten bespritzte der Priester alles mit Wasser aus einem anderen Gefäss, das er von dem Altar nahm. Wieder wurde eine Schüssel gebracht (Tetampa), auf dieser lagen Früchte, Stränge Zwirn, Geldrollen aus alten Münzen (alte Chinesisehe Kupfermünzen mit einem Loch in der Mitte, jetzt noch auf Bali und Lombok in Gebrauch) und zwei Armbänder aus solchen Münzen (Pitjis). Der Priester bespritzte auch dieses mit Wasser, nahm wieder etwas Reis und berührte damit die älteste Frau an der Stirne, an der rechten und der linken Schulter und endlich an Rücken und Brust, worauf er ihr, stets weiter betend, einen Strang Zwirn um den rechten Arm that. Sie that darauf dasselbe bei einigen Familiengliedern, und der Priester bei Bräutigam und Braut, denen er aber statt des Zwirns die Armbänder aus Münzen um den Arm that.

Fünfmal berührte der Priester nach Obigen also den Körper mit Reis, man glaubte dabei dass eigentlich fünf verschiedene Götter den Menschen anrührten (Domis). Vier derselben trugen dieselben Namen wie die, welche wir im Gebete beim Todtenfest nennen werden (S. 127),

1 Wahrscheinlich waren es Danglublätter (Engelhardtia aceriflora); der Danglubaum ist der heilige Baum der Těnggĕresen, man findet ihn auf den Kirchhöfen und den Danjangs (heiligen Hainen).

6e Volgr. IX. 
nämlich: Brama, Visnu, Sjiwa und Batoro-Mohodewo, der fünfte aber heisst hier Batoro-guru statt Batoro-Seworo. Domis meint, dass diese Namen fünf Urstoffe versinnbildlichen, sagt aber selbst dass die Namen nicht immer in gleicher Weise angegeben werden; beim Bromofest werden wir wieder etwas andere Namen kennen lernen.

Mit der letzterwähnten Ceremonie ist die Ehe geschlossen, Braut und Bräutigam setzten sich nun nebeneinander in das geschmückte Zimmerchen neben den Heerd. Jetzt mussten die Geister der Vorfahren noch ihren Anteil am Feste erhalten. Dazu setzte sich der Priester vor den Puppen nieder, verrichtete ein langes Gebet und besprengte die Puppen mit Wasser, dann tanzten das junge Paar und ihre Angehörigen vor den Puppen auf und nieder, setzten sich dann auch vor ihnen auf die Erde und begrïssten sie wie beim Todtenfest vergl. S. 127 (Sembah). Braut und Bräutigam kehrten nun an ihren Platz zurïck, wobei sie Sirih auf die Bank vor den Puppen hinwarfen. Dann wurden diese weggebracht, zuweilen erst den folgenden Morgen in der Frühe; vor sie dazu entkleidet wurden erhob sich ein lautes Weinen und Schreien, denn da die Vorfahren gekommen waren, um an dem Feste Teil zu nehmen, konnte man sie nicht, ohne lauten Schmerz zu zeigen, weggehen lassen.

Die Puppen wurden verbrannt. ${ }^{1}$ Gegen Abend trug man das junge Paar nach draussen, stellte den Bräutigam vor einen Stein (Batu giling) ${ }^{2}$ worauf man ein $\mathrm{Ei}$ mit boreh-boreh beschmiert gelegt hatte. Das Ei musste er nun mit dem Fusse zerschlagen und mit dessen Inhalt bestrich die Braut seine Füsse. Darauf wechselten beide ein Sirihblatt mit Reis, der Dukun gab beiden ein Waringinblatt ${ }^{3}$ mit Wasser, das sie zum Munde führten ohne zu trinken, alle gingen darauf wieder ins Haus. ${ }^{*}$

' Diese Rolle spielen jetzt die Puppen nicht mehr bei einer Hochzeit, auch könnte es wohl sein, dass mit dieser durch v. Herwerden beschriebenen Hochzeit ein Slamatan-Njewu (Todtenfest) combiniert war, bei der die Verehrung der Puppen ja Hauptsache ist. Aus Sparsamkeitsrücksichten, oder bei Geldmangel kommen solche Combinationen noch heute vor. Aber doch gehören die Puppen in abgelegenen Dörfern noch heute zur Ausschmückung des Hauses der Braut, aber man beachtet sie nicht weiter.

2 Batu giling darf man den Stein wohl nicht nennen, denn der Stein für die Gilingan ist ein anderer als der für die Pipisan und letzterer wurde benutzt (Sieh: Anmerkung 4).

3 Das wird wohl kein Waringinblatt gewesen sein, da dieser Baum hier nicht gedeihen kann. Vergl. Anm. S. 113.

4 Dieses Zertreten eines Eies wird noch jetzt geübt aber meist innerhalb des Hauses in dessen Mitte. Dorthin legt man den harten Stein (ma-maän), 
Nun verteilte man alle Speisen (mit Ausnahme des Reis) in 25 gleiche Haufen; alle setzten sich, der Bräutigam nahm ein Sirihblatt, rollte es auf, tauchte es in ein vor ihm stehendes Töpfchen mit Öl und Reis und bespritzte nun alle Speisen. Braut und Bräutigam machten nun eine Reverenz (Sembah) vor den Speisen; der Bräutigam nahm wieder das Öltöpfchen in die Hand, die Braut tauchte darin ein aufgerolltes Sirihblatt und berïhrte damit die Höhlung der Hände ihrer Eltern, die aufstanden und das Öl an der Hauptthïre wieder abrieben und sich dann wieder setzten. ${ }^{1}$ Nach einer kurzen Pause wurden nun grosse leere kupferne Töpfe hereingetragen und auf die Erde gesetzt, in diese legten nun zunächst die nächsten Verwandten, dann die anderen Gäste ihre Geschenke nieder; Geldstïcke (duiten), Kleider, Tüicher, Stïcke Zeug u. s. w. Jeder sprach dabei einige Gliickwünsche aus, dieser Gebrauch kommt heute noch vor, aber er ist selten geworden; ich sah dass die Geschenke (Sedepan) zu den Brautleuten in das Kämmerchen gelegt wurden, auch erzählte man mir dass die geschenkten Geldstïcke besonders glïckbringend seien, sodass man sie so lange wie möglich verwahre-(Heckpfennige) und nur bei Noth ausgebe, die geschenkten Kleider aber werden benutzt.

Heute ist es, wie auf ganz Java Sitte, dass die eingeladenen Gäste bei Festen Geschenke geben, meist nur Geld und zwar bei einer Hochzeit nicht für die Brautleute, sondern für den, der das Fest gieht. Giebt einer, der friher Gast war, nun selbst ein Fest, dann giebt der vorige Festgeber genau denselben Betrag, den er von ihm erhalten hatte. Bei grossen Festen, die viel Besuch locken, ist die Gesammtsumme der Geschenke oft grösser als die Auslage ${ }^{2}$, sodass es vorteilhaft sein kann ein Fest zu geben, dies wird

der zum Pipisan (Steinmühle) gehört; auf diesen legt man ein Sirihblatt und auf dieses das Ei. Der Bräutigam setzt die Ferse auf den Rand des Steines, die Braùt kniet neben ihm nieder und küsst den Fuss zum Zeichen der Unterwerfung; nun drückt er den Fuss kräftig auf das Ei, dass es zerplatẓt (vielleicht ein Zeichen der Gewalt oder Bedrohung der Braut) und die Braut bestreicht seine Füsse mit dem Inhalt des Eies (letzteres geschieht jetzt nur noch selten).

1 In Dorfe Ngadisari bestreicht man nicht nur die Hände der Eltern, sondern aller Gäste, aber mit trocknem Kalk, nur die Eltern reiben den Kalk an den Thürpfosten wieder ab.

2 Dies gilt natürlich nicht für den einfachen Dorfbewohner, die Zahl seiner Freunde und Familienglieder ist zu gering, ihre Gaben werden nur die Hälfte oder ein Drittel der Auslagen decken. 
natürlich von Priestern und Dorfsoberhäuptern sehr zu ihrem Vorteil ausgebeutet, denn besonders bei den Festen der letztgenannten wagt es Niemand fort $\mathrm{zu}$ bleiben. Ein Hochzeitsschmans dauert meist recht lange und zwar bis zum nächsten Morgen, zuweilen folgt am nächsten Tage oder noch an demselben Abend ein zweites Fest (nur eine Schmauserei) im Hause des Bräutigams. Die erste Nacht war darum meist auch nicht die prima Nox, sondern erst die Zweite. Man brachte die Brautleute in der zu Anfang beschriebenen Weise in ihre Wohnung.

b. Rechtsverhältnisse in der Ehe. Wie oben bereits erwähnt wurde, wird kein Kaufpreis für die Frau gezahlt; es gab der Mann der Frau aber Tausend Keteng (jetzt erhält sie garnichts mehr, obgleich die Summe noch stets bei der Eheschliessung genannt wird). Nach der Heirat ziehen die Neuvermählten in das Haus des Vaters der Braut, den der junge Mann jetzt als Vater betrachtet, dem er gehorchen muss, und dem er bei der Arbeit behülflich ist. So lange bleiben alle Schwiegersöhne mit allen ihren Kindern im Hause des Schwiegervaters wohnen, bis ein Schwiegersohn, meistens der älteste wohlhabend genug geworden ist um sich ein eignes Haus zu bauen. Wenn nur ein Schwiegersohn im Hause ist, dann bleibt dieser stets bei den Eltern seiner Frau, entweder bis ein neuer Schwiegersohn seine Stelle einnehmen kann, oder bis die Eltern gestorben sind, der ganze Nachlas fällt ihm dann zu. Heiratet ein älterer Mann (ein Wittwer), der bereits sein eignes Haus besitzt, daun zieht er nicht zu seinem Schwiegervater sondern bleibt im eignen Hause wohnen. Die Eltern bestimmen nicht die Ehen, die Kinder sind ganz frei bei der Wahl; hat sich ein Paar zusammengefunden so teilen sie ihren Wunsch den Eltern mit, welche die Hochzeit bezahlen.

Fast nie heiratet man ausserhalb seines Dorfes (Endogamie), während die Javanen Exogamie vorziehen. Sind viele Schwiegersöhne in einem Hause und keiner im Stande einen eignen Heerd zu gründen, herrscht dabei Armut durch die vielen Kinder, dann kann ein Schwiegersohn in das Haus seines eignen Vaters ziehen, wenn dieser wohlhabender ist oder ein grösseres Haus hat.

Bei der Eheschliessung bezahlen die Eltern der Braut und des Bräutigams jeder die Hälfte der dem Priester zustehenden Summe, beide können auch gemeinschaftlich die Ausgaben für die Hochzeit tragen, oft giebt nur der Vater der Braut die Hochzeit, oft feiert man doppelt bei beiden Eltern. Der im eignen Hause woh- 
niende Wittwer bezahlt selbst das Fest; das dem Priester verschuldete wird die Braut oder ihre Eltern aber auch in diesem Falle meist zur Hälfte bezahlen, wenn sie nicht ganz arm ist.

Die jungen Leute heirateten früher lieber mit Wittwen, jetzt ziehen sie wie die Javanen die Jungfrauen vor. Wenn man den älteren Mitteilungen glauben darf, dann hatte jeder Tĕnggĕrese früher nur eine Frau, wie auch jetzt noch in abgelegenen Dörfern. Trotsdem behauptet der Priester, dass es stets erlaubt gewesen sei zwei Frauen zu haben '. Es steht fest, dass es einen grossen Überschuss an Frauen im Gebirge giebt, diese sind denn auch durchaus nicht wählerisch, sie nehmen den ersten den besten, wenu sie nur einen Mann bekommen. Hat ein Maun zwei Frauen, dann hat jede eine eigne Schlafkammer; bei der erst gewählten Frau muss er zehn Tage liegen dann bei der zweiten fünf Tage u. s. w., auch von den Speisen und dem Gelde erhält die erste Frau etwa zwei Drittel die zweite ein Drittel, hat die Zweite aber mehr Kinder als die erste dann bekommt sie eben so viel oder noch mehr als diese. Haben beide eine gleiche Anzahl Kinder dann bekomnt die erste den grösseren Anteil. Die Schwangerschaft ist kein Hindernis für den Coitus, viele Männer ziehen es jetzt übrigens vor während der letzten. Monate andere Weiber zu besuchen. Im Allgemeinen sind auch die F'rauen sehr frei und lässt man auch die Töchter ihren Wünschen folgen. Wo viele Europäer sind kommt es heute auch vor dass Frauen und Mädchen um des Geldes willen von den Männern der Unzucht in die Arme geführt werden.

c. Ehescheidung. Diese kam früher sehr selten vor; in abgelegenen Dörfern wird auch heute ein Mann sich selten mehr als einmal von einem Weibe trennen lassen und bleiben die meisten der Jugendfreundin treu. Wo die Europäische oder Javanische Cultur aber hereindrang scheidet man sehr häufig, oft auch um sich später wieder $z u$ vereinigen, darum hat man auch die Scheidung kostspieliger gemacht, man muss jetzt das zehnfache bezahlen von der früher benötigten Summe, diese war 7 Wang Steng gleich 25 Cent. Scheidet man auf gegenseitigen Wunsch, dann bezahlt der Mann die Auslage an den Priester, will der Mann nicht scheiden aber die Frau wohl, dann findet auch Schei-

1 Wenn dieses Gesetz ein neues ist, dann wurde es wohl für die Priester durch die Priester erfunden, da diese meist als die Wohlhabendsten zwei Frauen besitzen. 
dung statt, aber die Frau bezahlt nun alles. War die Ehe kinderlos dann erhält der Mann zwei Drittel des Besitztums, die Frau ein Drittel, denn sagt man, die Frau trägt immer nur mit eine Schulter "im Slendang" (Tragband), der Mañu benutzt abwechselend beide Schultern, wenn er Lasten an einem Stock "Pikulan" trägt.

Ist die Frau damit nicht zufrieden, dann kann sie sich beim Priester beschweren, der untersucht dann ob sie dem Mann viel bei der Feldarbeit geholfen habe; ist Letzteres der Fall gewesen, dann erhält sie die eine Hälfte des gemeinsamen Besitzes. War die Ehe mit Kindern gesegnet, dann erhalten die Kinder bei der Scheidung, wenn gleich geteilt wurde, etwa die Hälfte von einem Eltern-Anteil (z. B. Vater 40 pCt. Mutter 40 pCt. Kinder 20 pCt.), erhielt der Vater mehr als die Mutter, dann bekommen die Kinder ungefähr halb so viel wie der Vater (z. B. bei 12 Gulden Vermögen, erhält der Vater 6, die Mutter 3 und die Kinder auch 3). Hat ein Mann zwei Frauen und lässt sich von einer scheiden, dann wird das gesammte Besitztum taxiert und erhält die verabschiedete Fräu wenigstens ein Drittel. Genaueres bestimmt der Priester, der untersucht wie viel die Frau, durch ihre Arbeit bei der Landwirtschaft, das gemeinsame Besitztum vergrössert hat. Von den Kindern folgen bei der Scheidung die eine Hälfte dem Vater, die andere Hälfte der Mutter; man überlässt die Wahl meist den Kindern, sodass zuweilen die meisten dem Vater folgen, in anderen Fällen der Mutter; die Kinder unter fünf Jahren bleiben stets bei der Mutter. Hat die Familie ein eignes Wohnhaus, so wird dies bei der Scheidung meist der Frau und ihren kleinen Kindern zugeteilt, da es dem Maun leichter fällt ein eignes Haus zu bauen. Alte Jungfrauen sind sehr selten, ich hörte nur von zwei unter einer Bevölkerung von 5600 Seelen.

d. Schwangerschaft. Arbeit der Frau. Während der ersten Monate darf die schwangere Frau nichts Erhitzendes geniessen, verboten sind Durian (Durio zibethinus), Nanas (Auanassa sativa), Lombok (Spanischer Pfeffer), Rudjak (scharfgewürztes Gericht), Maritja (Pfeffer), Djaë (Ingwer). Auch soll die Frau keine anstrengenden Arbeiten verrichten sonst droht ihr eine Fehlgeburt (Ka-inggatan, Kluron), die auch durch einen Fall verursacht werden kann. Man glaubt, dass das Kind die scharfen Speisen nicht vertragen könne. Ist doch eine Fehlgeburt eingetreten 
so wird diese begraben. Weder im Laufe der Schwangerschaft noch bei der Geburt gab man früher ein Fest, doch wurde das erwartete Kind im siebenten Monate der Schwangerschaft denselben fünf Geistern empfohlen, die beim Todtenfeste S. 127 genannt werden (Domis) und zwar nur durch des Dukuns Gebet. Jetzt giebt man wohl ein kleines Fest "Slametan Sagut", aber nur bei der ersten, dritten, fünften u. s. w. Schwangersehaft.

Ein kleines Fest wird auch wohl sieben Tage nach der Geburt gefeiert (Domis) wobei das Kind durch ein Gebet dem Schutze der Geister: Kaki (Kaké?) Among, Nini (Nènè?) Among, Kaké Djurutulis, Ninni Djurutulis, Kaké Rodjo Niti, Nini Rodjo Niti übergeben wird. ${ }^{1}$ Bei diesen Gebeten darf auch ein alter Mann den Priester vertreten, wohl weil letzterer dafür doch keine Geschenke erhalten würde.

Bei der Geburt sieht man nur männliche Hülfe; der Gatte muss stets den Kopf der Frau stuitzen. Die männlichen Helfer (auch Dukun genannt, hier gleich Aerzten) sind absolut unwissend. Auf die Hülfe bei und nach der Geburt, die Behandlung des Junggeborenen, will ich hier nicht weiter eingehen, denn diese anthropologischen Fragen habe ich bereits in einer anderen (oben S. 87 citierten, Janus 1897) Arbeit ausführlich beantwortet. Die Frau führt den Haushalt, sorgt für das Waschen der Kleider und für das Essen, pflegt die Kinder und holt las Wasser am Brunnen. Ausserdem hilft sie dem Mann bei der Feldarbeit, und desto eifriger sie dort hilft, desto höher wird sie geschätzt, die grössere oder kleinere Anzahl ihrer Kinder hat keinen Einfluss auf ihren Wert. Im allgemeinen ist ihre wirtschaftliche Stellung ganz gleich der des Mannes, dem sie durchaus nicht unterthänig ist.

\section{Das Kind.}

Dem Neugeborenen werden alle Haare ausser denen des Haarwirbels am Hinterkopf abrasiert, sonst wïrde das Kind krank werden und sterben. Nach dem $6^{\text {sten }}$ Jahre lässt man bei Mädchen die Haare wachsen, Knaben werden oft bis zum 8 oder 10 Jahre noch rasiert. Feste feiert man weiter nicht, so ist auch das Fest "der ersten

1 Aus diesen Worten geht hervor, das man zu Domis Zeiten dasselbe Gebet sieben Tage nach der Geburt benutzte, welches heute noch hergesagt wird wenn dem 10 Jahre alten Kinde die Haare abgeschnitten werden (Tugel Kuntjung, sieh Seite 120). 
Berührung der Erde" hier unbekannt. Erst wenn das Kind 8 oder 10 Jahre alt geworden ist, giebt man ein Fest Tugel Kuntjung; die Haare hat man vorher wachsen lassen und bei diesem Feste schneidet der Dukun einige Haare an der Stirne ab, über die er vorher einen Ring gezogen hat. Er schneidet dreimal und murmelt dabei ein Gebet.

Man denkt sich dabei, dass man eigentlich dem jungen Kinde alle Haare hätte abschneiden sollen; da man nun die des Haarwirbels stehen liess, die man als geliehene betrachtet, so müssen später Haare an anderer Stelle abgeschnitten werden. Gleich nach der Geburt erhält das Kind einen Namen, ohne weitere Ceremonien. Fïr ein Mädchen wählt man den etwas umgebildeten Namen des Vaters, für einen Knaben den Namen der Mutter, de:n man eine männliche Endsilbe giebt. Bei diesen Umänderungen ist man allerdings sehr frei, sodass oft nur die ersten beiden oder nur der erste Buchstabe der gleiche bleibt wie aus folgendem Verzeichnis hervorgeht:

$\begin{array}{llll}\text { Vaternamen. } & \text { Tochternamen. } & \text { Mutternamen. } & \text { Söhnenamen. } \\ \text { Amir } & \text { Amidah } & \text { Djah } & \text { Djahiman } \\ \text { Dur } & \text { Durimah } & \text { Djimah } & \text { Djimo } \\ \text { Giso } & \text { Gisah } & \text { Warsinten } & \text { Warso } \\ \text { Garmo } & \text { Garsi } & \text { Kasirah } & \text { Kasirun } \\ \text { Naimin } & \text { Naimi-Nainten } & \text { Ratni } & \text { Raiman } \\ \text { Alinodin } & \text { Alimah } & \text { Dasilah } & \text { Djaimin } \\ \text { Burun } & \text { Bajinah } & \text { Dasinten } & \text { Darmin } \\ \text { Gadri } & \text { Gami } & \text { Rupiah } & \text { Radio } \\ \text { Ratmo } & \text { Rasinah } & \text { Pinah } & \text { Paiman } \\ \text { Sadipo } & \text { Santi } & \text { Antirah } & \text { Adin } \\ \text { Adun } & \text { Amunah } & \text { Amirah. } & \text { Andarmo. } \\ \text { Aiman } & \text { Anti } & & \\ \text { Setro. } & \text { Satimah } & & \end{array}$

Diese Umänderungen werden von dem Familienvater bestimmt, dabei kann man aus einem Namen zahllose Umänderungen bilden, natïrlich haben die Namen dabei jede Bedeutung verloren. ${ }^{1}$ Zuweilen wählt man auch bekannte Namen, die dem Klange nach gefielen, auch ohne deren Bedeutung zu kennen. Daher findet man heute bereits manche Arabische Namen und in seltenen Fällen auch den

1 Durch diese Umänderungen ist die Zahl der Namen auch unbeschränkt gross

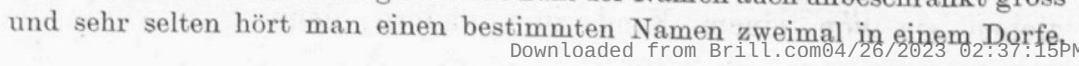


Wochentag der Geburt als Namen; da mau dann aber die Malaischen Namen und nicht die alten der Tĕnggěresischen Zeitrechnung wählt, so geht bereits hieraus hervor, dass der Gebrauch recenten Datums ist. Das Kind behält seinen Namen bis es selbst Vater oder Mutter wird, denn die Eltern nennen sich nach dem ältesten Kinde: Pak A, und Bok A. Die männlichen und weiblichen Namen unterscheiden sich nur durch die Endsilbe oder den Schlussbuchstaben, so deuten $o$, an uvd di am Ende stets einen Mann an; ni, em, lem, eine Frau; andere Endsilben könneiı aber bei Namen beider Geschlechter vorkommen, so fand ich die Endsilbe all bei 120 Franen und nur bei 2 Männen, $i k$ bei 13 Männer und 23 Frauen; daraus geht hervor dass die Namen sich nicht streng in männliche und weibliche trennen lassen und kann ein Tĕnggĕrese, wenn er die Person nicht kennt, oft nicht mit Bestimmtheit sagen ob der Name einen Mann oder eine Frau andeutet. Über die Beschneidung, die ihneu ursprïnglich unbekanut war, findet man näheres unter "Gottesdienst".

Die Kinder erhalten kaum irgend welche Erziehung, sie lernen etwas gehorchen und adat ist, sowie sie dazu im Stande sind, werden sie angehalten bei der Arbeit zu helfen. Die kleinen Mädchen bewachen die jüngeren Geschwister, die sie meist auf dem Rïcken herumtragen. Erwachsene Frauen tragen ein Kind indem sie es auf die eine Hiifte setzen und mit einem Tuch (Slendang) stuitzen. Die kleinen Knaben werden besonders zum Grasschneiden angehalten, um Futter für die Pferde und Kïhe herbei zu schaffen.

Die Spiele der Kinder unterscheiden sich nicht von denen der Javanischen Kinder.

\section{Die Eltern, das Erbrecht, die Adoption.}

Wenn die Eltern alt geworden sind und es wohnt ein Schwiegersohn im Hause. dann wird dieser für sie sorgen und sie mit Ausschluss aller andern Kinder beerben. Ist kein Schwiegersohn und auch sonst kein Kind im Hause und wünschen die Eltern das Haus nicht zu verlassen, dann fordern sie eines ihrer verheirateten Kinder auf zu ihnen zu ziehen, von diesem werden sie dann verpflegt und dafür wird es ihr einziger Erbe sein. Wollen sie nicht in ihrem Hause bleiben dann ziehen sie zu einem ihrer Kinder und zwar zu dem, welches sie am meisten lieben. Nię ziehen sie von einem Kind zum andern, denn dann würde die 
Erbschaft und das Begräbnis schwierig zu regeln sein, die stets auf das Kind fallen das die Eltern verpftegte. Würden sie hin und her ziehen, dann würde man nicht wissen, wer nun für das Begräbnis sorgen muss. Auch wenn die Eltern arm sind und das Kind, zu dem sie in's Haus zogen, auch arm ist, wird doch dieses Kind allein für das Begräbnis sorgen, nie wird es reichere Geschwister um Hülfe bitten, doch bieten diese zuweilen aus freien Stiicken eine Unterstïtzung an. Wenn die Eltern Streit bekommen mit dem Kind, das sie verpfleyt, dann verlassen sie das Haus und ziehen zu einem andern Kinde, sterben sie dann bei diesem, dann ist dieses der einzige Erbe, wenn auch das andere Kind, bei deın die Elteru eıst wohnten, schon viele Jahre für die Eltern gesorgt hatte. Stirbt der Vater oder die Mutter dann erhält der (oder die) Überlebende, wenn er oder sie noch Arbeitsfähig ist, alles, dessen (deren) freien Willen es überlassen bleibt, ob er (sie) den Kindern etwas abgeben will. War die Ehe kinderlos, dann behält auch der längstlebende alles, die Eltern des (oder der) Verstorbenen haben gar keine Rechte auf die Erbschaft, auch dann nicht wenn sie den Kindern grössere Geschenke gegeben haben. Die Eltern köunen nämlich, wenn sie alt werden, ihr Besitztum unter die Kinder ganz nach ihrem Wunsch verteilen, doch werden sie stets einen Teil behalten, welches dem sie verpflegenden Kinde zufällt. Wenn der Vater stirbt und die Mutter ist nicht mehr arbeitsfähig, dann erhält jedes Kind aus dem Nachlass eben so viel wie die Mutter (also bei 5 Kindern erhällt die Mutter nur ein Sechstel) und zwar erhalten alle Kinder (kleine und grosse) gleiche Teile; die Mutter zieht dann zu einem der Kinder, welches dann nach ihrem Tode ihren Nachlass erhält und für das Begrïbnis sorgen muss. Stirbt die Mutter dann behält der Vater, auch wenn er nicht mehr Arbeitsfähig ist, alles; dasjenige der Kinder, welches fuir ihn sorgt bis zu seinem Tode, ist dann sein einziger Erbe. Stirbt ein kinderloses Ehepaar dann teilen die Eltern die Erbschaft zu gleichen Teilen, lebt eines der Elternpaare nicht mehr dann treten die Brïder und Schwestern an dessen Stelle. Wenn die Mutter eines Säuglings stirbt, dann wird dasselbe von einer Tante oder einer fremden Frau als Kind angenommen. Der Vater verliert alle Rechte auf dieses Kind. Die Pflegemutter sorgt auch für die Hochzeit des Kindes. Eine kinderlose Frau adoptiert gerne ein Kind einer Kinderreichen Familie, zuweilen adoptiert auch eine junge Frau, welche ihr erstes Kind verlor, das Kind einer andern um sich zu trösten. 


\section{Gebräuche bei Todesfällen. Begräbnis und Todtenfeier.}

Gleich nach dem Tode und nachdem das laute Klagen der Anverwandten nachgelassen hat, bringt man die Leiche auf einer Bank nach draussen; dort wurde sie friiher (van Herwerden) vom Priester gewaschen, jetzt besorgen die Verwandten dieses Geschäft und zwar nicht auf einer Bank, sondern die Familienglieder halten die Leiche in den Händen. Diese wird dann in weisses Leinenzeug gewickelt, dann bringt man die Leiche zurïck in's Haus, der Kopf der Leiche wird gleich dem Bromo zugewendet und neben sie legt man die Speisen, die der Verstorbene am liebsten ass; an der Bahre sprach der Priester früher ein kurzes Gebet.

Noch vor dem Untergang der Sonne oder, wenn der Tod Abends eintrat, am folgenden Morgen wird die Leiche auf einer offenen Bank (ohne Dach) zum Kirchhof gebracht, wo die Grube bereits fertig ist. Man legt die Leiche so in das Grab, dass der Kopf in der Richtung des Bromo liegt, auch drehte man früher das Gesicht noch so, dass es nach dem Bromo blickte.

Die Leiche wird mit Brettern oder einem starken Bambugeflecht bedeckt, damit die Erde, womit man die Grube schliest, nicht direkt auf die Leiche falle. Vor die Leidtragenden das Grab verlassen rufen alle "Surah", dann folgt ein Gebet des Priesters und wenn dieses zu Ende ist ruft einer: "Pepek batu" (sind wir noch vollzählig, noch alle bei einander) und eine Stimme antwortet: "Pepek sidji dudu batu" (einer von uns ist nicht mehr da). Dann gehen sie nach Hause, am Ende des Kirchhofweges steht ein Familienglied des Verstorbenen und giebt jedem, der am Begräbnis Teil nahm, ein kleines Geldgeschenk. Es folgt ein kleiner Schmaus im Sterbehaus "Slamatan nusur tanah" oder "Slamatan sipat lepuh" genannt.

Auf dem Grabe stellt man am oberen und unteren Ende ein hölzernes Zeichen (maesan), es ragt nur wenig über der Erde hervor und ist häufig mit kleinen Schnitzereien verziert. Gleich hinter dem oberen Zeichen (also Fusswärts von diesem) wird ein dünnes Bamburohr in die Erde gesteckt, dorthin, wo vermutlich der Mund der Leiche liegt, in dieses giesst man die ersten sieben Tage nach dem Begräbnis etwas Wasser und schliest die Röhre am siebenten Tage. Auch bringt man sieben Tage lang Speisen zum Kirchhof; meist legt man diese auch in die Höhlung eines dickeren aufrechtstehenden Bamburohrs, andere legen die Speisen 
auf Pisangblätter oder giesen sie auf die blosse Erde. Auch die Kleider des Verstorbenen werden sieben Tage lang zum Kirchhof gebracht, aber man bringt sie jeden Tag wieder in's Haus zurïck. Der auf dem Kirchhof hausende Geist (sie unten) ist Zeuge dass alles ordentlich geschieht; die Gräber werden stets von den grossen Danglubäuınen beschattet (Engelhardtia aceriflora). Die Begräbnisse sind die gleichen für arme und reiche Leute auch für die Priester, nur ist bei letzteren, wie bei Beambten, die Zahl der zum Kirchhof ziehenden Leidtragenden eine grössere.

Am siebenten Tage giebt man das erste Todtenfest. Man macht dazu eine Puppe aus Blumen, die den Todten repesentiert, legt vor diese seine Lieblingsspeisen und seine Kleider und ruft ihn bei Namen, dass er zurïckkehre, esse und seine Kleider wechsele. Wenn der Verstorbene an einer Krankheit litt, die eine Schwellung des Leibes (allgemeine Hydrops) verursachte dann macht man zwei Puppen, damit die Krankheit nicht auf einen Gesunden übergehe. Vor der Puppe spricht der Priester ein Gebet, während er ein Stiick Dupå (Weihrauch) in der Hand hält.

Dan legt er den Weihrauch in die glühende Asche von Reisstroh und während der Rauch aufwärts steigt murmelt er ein zweites Gebet, dessen Inhalt ihm ebenso unverständlich ist wie das Erste.

Wie immer wird während des Gebets auch Weihwasser gesprengt. Das Fest verläuft weiter wie alle anderen mit einer ruhigen Schmauserei, dabei hört man noch oft das Weinen der nächsten Verwandten. Zum Schluss wird die Puppe aufgenommen und entkleidet, das Weinen und Schreien nimınt zu, einer der Familienglieder sagt: "Warum verlässt Du uns, wir hätten dich gut versorgt", dann bringen die ältesten Männer des Dorfes, die auch die Puppe angefertigt haben, sie nach draussen und verbrennen sie an heiliger Stelle. Nach Ablauf dieser Feierlichkeit wird das Grab nicht mehr regelmässig besucht, einige Leute bringen jedoch bei jedem häuslichen Fest noch Speisen zum Kirchhof.

Aber die Geister der Verstorbenen erreichen nach diesem Fest den Himmel noch nicht, sie bleiben an der Schwelle, dem Mungal, ${ }^{1}$

1 Dieses gilt wohl nur für die Geister der Verstorbenen der Nordseite des Gebirges (Tosari und Umgebung), welche, um zum Bromo zu gelangen, am Mungal vorbei müssen; wo die Geister der Todten aus den anderen Gegenden des Gebirges den Eintritt in das Fegefeuer des Bromo abwarten blieb mir unbekannt; die Dörfer der Nordseite sind übrigens die ältesten, und dort entstand wohl die Sage. 
von wo man in das. Sandmeer hinabsteigt, welches den Bromokrater ungiebt. Dort haust der Geist des Raden Demeling, dem man gerne opfert bevor man in das Sandmeer hinabsteigt, besonders wenn man den Smeru ersteigen will; man legt etwas Speisen oder Taback in die kleinen Höhlungen, die sich in den Felsenwänden zu beiden Seiten des Passes finden.

Um den Seelen in den Himmel zu helfen ist das grosse Todtenfest "Njewu" nötig. ${ }^{1}$ Dieses giebt man nicht an einem bestimmten Tage nach dem Tode, sondern zu einer Zeit, wo man genug Geld hat, denn diese Feier kostet wenigstens 150 Gulden, meist noch viel mehr. Sie darf nur im fünften oder sechsten Monat des Jahres gehalten werden und muss wenigstens zwei Tage und zwei Nächte dauern. Man feiert meist gleichzeitig für mehrere verstorbene Familienglieder, von denen einige zuweilen schon viele Jahre todt sind, wenigstens soll ein Jahr nach dem Tode verstrichen sein. Wenn das nötige Geld vorhanden ist giebt man das Fest so bald möglich, da es den Kindern und Enkeln Segen bringt: darum wird auch jedes Kind, auch wenn es viele Geschwister hat, diese Gedächtnisfeier für seine Eltern herrichten, sobald es erwachsen ist und über die Mittel verfügt.

$\mathrm{Zu}$ diesem Fest werden eine grosse Anzahl Puppen gemacht, die ersten beiden sind die Akal Bakal, die auf dem Kirchhof hausenden Schutzheiligen des Dorfes ${ }^{2}$; die anderen representieren zunächst die Verstorbenen, für welche das Fest gegeben wird; jeder von diesen hat zwei Begleiter (Saksi) bei sich, die aus den verstorbenen Angehörigen gewählt werden (Eltern oder,Kinder) und dann weiter eine Anzahl beliebiger Vorfahren. Ihre Anzahl ist bei grossen Festen auf zwei und vierzig festgesetzt. ${ }^{3}$ Die männlichen Puppen tragen ein Kopftuch, die weiblichen ausgefaserte Blätter als Haare am Kopfe. Alle diese Puppen sitzen in einer langen Reihe neben einander auf der langen Bank, vor ihnen stehen allerlei Speisen.

Die Todten, denen das Fest gilt, werden ausser durch Puppen

1 Es wurde mir nicht recht deutlich ob die Seelen durch dieses Fest vom Mungal in das Fegefeuer des Bromo gelangen, oder vor diesem schon im Bromo waren und nach demselben zum Himmel des Smeru fliegen.

2 Der männliche Akal Bakal (für Tosari "Trukå Bumi") trägt ein weisses Kleid und ein weisses Kopftuch.

's Auch die Badujs machen Puppen zum Laksafest, welehe aber nicht Todte sondern die Lebenden representieren. 
auch durch lebende Menschen repräsentiert, welche an einer anderen Seite des Hauses (unter dem Sanggar S.102) auch in einer Reihe auf einem Baumstamm sitzen, wobei ihre Kopf und Rücken mit einem weissen Leichentuch bedeckt ist. Der Representant muss von gleichem Geschlecht wie der Verstorbene sein und wird aus den nächsten Verwandten gewählt. Vor diesen lebenden Representanten stehen ganz neue Küchengeschirre, vor jedem auch ein ganz neuer grosser Topf, in welche die Puppe (der andere Representant des Verstorbenen) gesetzt wird, die man beim Anfang der eigentlichen Feier dazu aus der Reihe der Puppen heraus nimmt, sie wird von dem lebenden Representanten am Kopfe festgehalten.

Zwischen den Küchengeschirren liegt eine geschlachtete Ziege und ein lebendiges Huhn und eine lebendige Ente und allerlei Speisen, weiter steht ein kurzes Bamburohr vor jedem Representanten mit einem Geldopfer. Auch liegen Speisen und Geldopfer auf dem Soller (Sanggar). Alle diese Geldopfer sind genau vorgeschrieben und heissen Sandingan. In jedem Bamburohr ein Satak (ein Satak = satu Atak $=10 \mathrm{Wang}=83 \mathrm{Cent}$ ) auf dem Soller 26 Idjeh (Idjeh ist die kleinste Niederländische Silbermünze im Werte

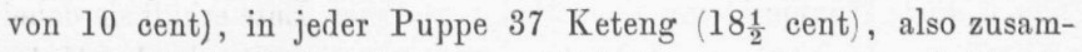
men für jeden Abgestorbenen $361 \frac{1}{2}$ Cent. Alle diese Geldopfer und die Speisen vor den Puppen und den lebenden Representanten, sowie das neue Küchengeschirr fallen nach dem Fest dem Priester zu, ein ganz kleiner Teil auch seinem Bedienten (Legen).

$\mathrm{Zu}$ der Feierlichkeit muss Reis in besonderer Weise gekocht werden. Man muss dazu ein neues Geschirr verwenden und das Feuer darf kein Holzfeuer sein, sondern es wird mit trocknen Djarakfrüchten (Ricinus communis) geheizt, die man durch kleine Stöckchen zu kurzen Schnüren vereinigt hat. Der Reis wird vom Weibe des Priesters und zwar nur halb gar gekocht. Während diese damit beschäftigt ist und nachdem die obenerwähnten Puppen in die Töpfe vor die lebenden Representanten hingesetzt. worden sind, setzt sich der Dukun vor diese nieder und murmelt ein langes Gebet, wobei er alles, was vor ihm steht, mit Weihwasser bespritzt. Dann steht er auf und stellt sich hinter die Representanten, also wo das weisse Leichentuch herabhängt. Sein Weib streut nun den halb gekochten Reis auf die Köpfe der Menschen, die unter dem Leiehentuch sitzen. Nun ergreift der Dukun das Huhn, schwingt es neun Mal über jeden Kopf, wobei es von dem Reis picken soll, dabei mumelt er wieder eine,Zanherformel 
Dann thut er dasselbe mit der Ente. Huhn und Ente werden nun weggebracht. Jetzt nimmt der Priester eine Nadel und zieht diese durch das Haar der vor ihm Sitzenden und gleichzeitig durch das Leichentuch, sie werden gleichsam in das Leichentuch eingenäht. Zum Schluss ergreift er einen brennenden Spahn und sengt damit einen Teil der Stirnhaare der Representanten, ich vermute dass dadurch eine Feuerbestattung angedeutet wird. Damit ist die Feierlichkeit beendet, man entkleidet die Puppen, wirft sie ganz gleichgültig auf einen Haufen, die ältesten Männer des Dorfes bringen sie ausserhalb des Hauses und verbrennen sie an dem oben genannten heiligen Ort. Früher erwies man den Puppen mehr Ehre. Bevor sie hinausgetragen wurden machte ihnen jeder seine Reverenz (Sembah), indem man sich mit gekreuzten Beinen vor ihnen auf die Erde niederliess und die beiden an einander gelegten Hände an die Stirne brachte, zwischen den Händen hielt man dabei heilige Blumen; dann erhob sich ein lautes Weinen und Schreien.

Neun Mal muss das Huhn und die Ente über jeden Kopf geschwungen werden, denn neun Öffnungen hat der Mensch an seinem Körper. Auf der geschlachteten Ziege reitet die Seele des Verstorbenen zum Himmel, von dem Huhn und der Ente erhält sie dabei den Reis als Nahrung und beide sind ihr wie Flügel, das Huhn an ihrer linken Seite, die Ente an ihrer rechten Seite ${ }^{1}$. Da die Ziege das Reitpferd der Seele ist, so müssen alle ihre Knochen und die Eingeweide in der Haut der 'Liege bleiben, man entfernt nur das Fleisch, welches aber auch in gekochtem Zustande (Saté) beim Feste gegenwärtig sein muss und auch dem Priester zufällt. Früher scheint man (Domis) am Ende des Festes eine Cocosnuss zerbrochen zu haben, auch behauptet dieser Autor, dass der Priester in seinem Gebet um Vergebung der Sünden bete, und dass die Seelen der Verstorbenen in ihren Nachkommen und Verwandten wieder erscheinen möchten, wobei er die Geister Betoro Bromo, Betoro Wisuu, Betoro Sjiwa, Betoro Seworo und Betoro Mohodewo anrufe.

\section{Gottesdienst.}

Die Hindus, welche Java viele Jahrhunderte beherrschten, gehörten zum Teil zu den Wisjnuïeten, zum Teil zu den Sjiwaiten. Die letzteren waren wohl in der Mehrzahl, da die Anzahl der Sjiwabilder alle anderen übertrifft. Sjiwa wurde auf Java aber meist mit dem

1 Es ist also das alte Sinnbild, die flüchtige Seele hat Aehnlichkeit mit dem beschwingten Vogel. 
Namen Batåra guru angedeutet, denn man verehrte ihn nicht als Vernichter sondern als Lehrer (Batårå guru) und als Lebenschenker im deın Syıbole männlicher Zeugungskraft, daher die Säulenförmigen Steine oder Lingga's. Es ist eigentümlich, dass man die Lingga's fast immer im Gebirge findet und zwar im Freien. Solche Tempel des Sjiwa-Lingga-cultus finden sich besonders in Ost Java auf den höchsten Bergesgipfeln. ${ }^{1}$ Die des Argopuro (Janggebirge) habe ich ausführlich beschrieben, ihnen sollen die auf dem Kawi und Ardjuno (Widodaren) ganz ähnlich sein (Junghuhn).

Auch auf dem Walirang, einem Neben-Gipfel des Ardjuno hat man Linggasteine gefunden (Zollinger). Von dem Ruinen auf anderen hohen Bergesgipfeln (Lawu, Tampomas u. s. w.) fehlen genauere Beschreibungen, doch scheint mir dass auch die meisten von diesen (pyramidenförmige Steine) dem Linggacultus geweihet waren. Heutigen Tages lässt sich nicht mehr ergründen warum die Linggaverehrer mit Vorliebe die höchsten Bergesgipfel wählten; auf anderen Bergen fehlen solche Trümmerstätten und merkwürdiger Weise werden sie grade auf dem Tĕnggĕrgebirge vermisst, wo sich am läugsien der Hinduglaube gemischi mit dem noch aiteren Heidentum erhalten hat Doch hat man unlängst beim bearbeiten eines Feldes in diesem Gebirge (in zwei tausend Meter Höhe) einen wirklich ganz vortrefflich aus Bronze gefertigten Penis gefunden (jetzt im Museum zu Batavia), die entblöste Eichel, die Testikel, alles ist gleich schön gearbeitet, das Ganze scheint eine Sirihkalkbüchse gewesen zu sein. Den jetzigen Bewohnern war die Bedeutung unbekannt, doch schrieben sie ihm sofort Einflus auf die Fruchtbarkeit der Familie zu, in deren Haus er aufbewahrt wurde, man verehrte ihn denn auch (la Chapelle). Man fand auch noch andere Beweise von Linggacultus, nämlich an Nordabhang des Gebirges bei der Dessa Lumbang ein Joni-Lingga (Hageman) und ausserdem wurde ein hoher schroff-abfallender Felsen bei Ngadisari (Residentschaft Probolinggo) ganz in der Nähe des centralen Kraters, früher Gunung Lingga genannt. Man sieht ihn gleich hinter dem kleinen Berghotel (Passanggrahan) von Ngadisari.

Sicher waren also auch die Vorfahren dieser Tĕnggĕresen Sjiwaitische Linggaverehrer. Den Einfluss der Hindus auf die Tĕnggĕresen erkennt man übrigens auch sofort an den Zodiakbechern ihrer Priester, die bei allen Feierlichkeiten eine grosse Rolle spielen,

I De Linggatempel en andere oudheden op het Yanggebergte. Tijdschrift v. h. Bataviaasch Genootschap. Deel XLI. afl. 1. 1899. 
und die ich früher in einer ausführlichen Abhandlung beschrieben habe ${ }^{1}$. Dass die Linggatempel grade auf den höchsten Bergesspitzen gefunden werden, wofür im Linggacnltus selbst, wie ich glaube, wohl keine Erklärung zu finden sein wird, erregt den Gedanken, dass dieser Cultus ein älterer ist und, von den nachfolgenden Auffassungen der Brahmanen und Buddhisten zurückgedrängt, auf diese Bergesgipfel sich zurück zog. Zwar könnte man auch annehmen dass der Linggadienst der zähste war, erst vor dem Islam auf die Bergesgipfel flüchtete und sich dort lange erhielt: solcher Annahme können wir aber entgegentreten, denn zu der Flucht vor dem Islam hatten die Bewohner Besuki's (welche die Tempel des Janggebirges bauten) keinen Grund, da sie zu dem Reich von Balambangan gehörten, das bis zur Mitte des vorigen Jahrhunderts unter Balinesischem Einfluss stand Auch sind die Tempel weit älter als der Islam auf Java. Das Fehlen von Tempeltrümmern im Tĕnggĕrgebirge ist wohl auch der Hauptgrund für die früher allgemeine aber ganz unrichtige Annahme, dass die Bevölkerung noch nicht lange auf ihrem Berge lebe und erst vor dem Islam dorthin aus der Ebene geflüchtet sei. So behaupteten schon Herwerden und Domis, dass die ersten Bewohner sich erst im Gebirge niederliessen nach der Zerstörung von Modjopahit durch den Islam.

Nach von Herwerden flüchteten sie unter ihrem ersten Anführer Kjahi Dadap Petak vor den Verfolgungen des Mohamedaners Raden Fatah. Domis giebt dem ersten Asführer einen noch längeren Namen, er nennt ihn Mulegmaring Tinger Kassera Kjahi Gede Dadap Petak (Puti). Er soll mit Leuten aus Modjopahit und Malang in dieses Gebirge geflüchtet sein. Als Stammvater der Tĕnggĕresen nennt er Kjahi Songo Buwono Mangkurat Mangku Negoro, doch war dies wohl einer ihrer Häuptlinge, und zwar derjenige, welcher die Dessa Tosari stiftete, wo noch heute das Grab eines Kjahi Gĕdé Songo Buwono gezeigt wird. Domis giebt aber zu dass alles ganz unsicher sei. Alte Leute erzählen aber noch heute dass ihre Väter nach der Zerstörung von Modjopahit ihrem nach Bali geflüchteten Fürsten hätten folgen wollen, dabei hätten sie aber einen verkehrten Weg gewählt, seien auf den grossen Krater "das Sandmeer" gestossen, den sie nicht gewagt hätten zu überschreiten. $\mathrm{Da}$ sie sich fürchteten zurückzukehren

1 De heilige bekers der Tenggereezen. Zodiakbekers. Tijdschrift voor Ind. Taal-, Land- en Volkenkunde. Deel XXXIX. 1897. 
seien sie in den Wäldern des Gebirges geblieben. Diese Erzählung klingt sehr wahrscheinlich, denu sehr wohl kann der fast eine geographische Geviertmeile grosse Krater die Flüchtlinge zurückgeschreckt haben, zumal der Rand des Kraters damals wohl nicht umgangen werden kounte.

Wir haben aber oben gesehen dass diese Erzählungen in ihrer Allgemeinheit nicht richtig sein köunen, denn die Tĕnggĕresen wohnter bei der Zerstörung des Reiches Modjopahit schon lange in diesem Gebirge. Sie können, wenn sie überhaupt historischen Grund haben, nur einen 'Zuzug von Flüchtlingen oder die Geschichte einer Häuptlingsfamilie erklären, wie ich oben (S. 93) bereits andeutete. Nehmen wir eine Vermischung mit Mudjopahitschen Flüchtlingen an dann würde dadurch erklärt sein, warum die Tĕnggĕresen den reinen Indonesischen Typus nicht mehr zeigen und den Javanen ähnlich wurden.

Eine zusammenfassende systematische Beschreibung der Tĕnggĕrresischen Glaubenssätze und Formen vermag ich nicht zu geben, alles ist $\mathrm{zu}$ verworren auch im Gedankengange der Priester. Anklänge an verschiedene. Lehren findet man in der nachfolgenden Beschreibung der Feste. Im Allgemeinen gilt: dass der Tĕnggĕrese sich die ganze Natur mit Geistern belebt denkt, die besonders in Kratern, auf Bergesgipfeln, bei alten Grabstätten, bei Wasserfällen hausen. Die meisten sind ihm freundlich gesinnt wenn er nur nicht versäumt ihnen die nötige Ehre zu erweisen. Diese Ehrbezeugungen können mancherlei Art sein. Die Umständlichste, die nur wenigen Geistern zu Teil wird, ist durch Feste, einfacher ist die durch Gebete, die heute meist nur durch den Dukun verrichtet werden; am weitesten verbreitet sind die kleinen Opferspenden, die meist nur aus einigen Blumen bestehen, seltener aus etwas Kautabak oder ein wenig Reis auf einem Pisangblatt.

Solche Opferspenden findet man am häufigsten bei Wasserfällen und bei Grabstätten.

Es haben diese Geister mancherlei Namen und grade in diesen Namen zeigt sich fremder Einfluss. Man begegnet hier all den Namen des Hindu-pantheon's ohne das ihre Bedeutung gewürdigt würde und jetzt wird auch oft der Name Allah in den Gebeten erwähnt. Soviel ist sicher, dass sie (wie andere Indonesier) das höchste Wesen Batoro Guru nennen. Nach Domis vermieden sie früher diesen Namen auszusprechen und nannten ihn statt dessen: Prabu Guru Ingluhur. Dieser höchste Geist belohnte alles Gute. Hageman spricht 
von einem persönlichen Gotte Sangjang Tunggal ' oder Batoro Guru, der nur als Unität von ihnen verehrt wird ${ }^{2}$. Jetzt glauben sie das Batoro Guru auf dem Smeru (dem höchsten Gipfel Java's (auch Mahameru genannt) lebe ${ }^{3}$. Zu ihm in den Himmel (Suronolio) ziehen die Geister der Verstorbenen, aber erst nach der grossen Todtenfeier (Njewu-fest). Darum ist es die erste Pflicht der Anverwandten zu sorgen dass dieses Fest gefeiert werde, damit die Geister zur Ruhe kommen. In der Zwischenzeit verweilen sie erst am Mungal, dem Pass, von dem man in das Sandmeer, das den Bromokrater umgiebt, hinabsteigt. Von dort ziehen sie zum Krater des Bromo, wo sie durch Feuer gereinigt werden, und endlich nach dem Fest zum Gipfel des Smeru ${ }^{4}$.

Für die andern Dewas kann ich keine Rangstufen erkennen, denn im Krater des Bromo, welcher ganz im Mittelpunkt ihrer Gedankenwelt steht und so sehr verehrt wird, leben, wie wir weiter unten sehen werden (Seite 140), so viele Geister, dass es nicht recht deutlich ist, welchem man eigentlich die Kraft des Kraters und so die grösste Bedeutung zuschreibt.

Am wichtigsten für's tägliche Leben sind die Geister, welche in der Nähe jedes Dorfes wohnen und als dessen Stifter angesehen werden. Bei jedem Dorfe liegen ein oder zwei heilige Gräber unter hohen Bäumen. Diese Geister bewachen ihr Dorf, dass ihm kein Unglïck zustosse, kein Brand, kein Diebstahl die Bewohner beunruhige.

Meist wohnt ein Dorfgeist auf dem Kirchhofe und einer an bestimmter Stelle an der entgegengesetzten Seite des Dorfes, sodass dieses wie von Schutzgeistern umgeben ist. Auf dem Kirchhofe von Tosari hausen Kjahi Anten und sein Weib Njahi Anten, welche bei gewissen Festlichkeiten eiue grosse Rolle spielen, denn bei jeder grösseren Todtenfeier (Njewufest) müssen die Vorfahren im Bilde gegenwärtig sein, und zwar unter der Leitung der beiden genannten Geister. Sie werden repräsentiert durch Puppen aus Blättern und

1 Batoro Tunggal ist auch der Hauptgott der Baduj's in West-Java; diesen hat man später, wie mir scheint, mit Batoro Guru d. i. Sjiwa identificiert.

2 Dem Namen Sangjang Tunggal begegnet man auch noch in den Gebeten.

3 Der Smeru ist dem Bromo angeschlossen. Nach Burer glauben die Tĕnggĕresen dass Mond und Sterne ihre Kreise um den Smeru beschreiben, ein ähnlicher Glaube soll aus Hindostan bekannt sein.

4 Die Tĕnggĕresen kennen also gleich den Baduj's ein Fegefeuer. Man vergleiche Dr. J. Jacobs en J. J. Meyer: De Badoej's. 's Gravenhage 1891. S. 38. 
Blumen und alten Lappen gefertigt, die man bei grössern Festen in eine lange Reihe neben einander setzt, man bewirtet und ehrt sie, wie wir weiter unten sehen werden. In soiner Puppengestalt heisst Kjahi Anten: Trukå Bumi und sein Weib: Njahi Pekalan; sie haben die ersten Plätze in der Reihe inne und Trukă Bumi trägt ein weisses Kopftuch.

Alle diese Puppen sind sehr roh gearbeitete Nachbildungen eines mit gekreuzten Beinen (silå) sitzenden Menschen ${ }^{1}$. Alle haben als Haare die faserigen Blätter der Arenpalme, aber die männlichen Puppen tragen um diese ein Kopftuch, die weiblichen ein Blumenkränzchen (de Wolff van Westerrode). Die Namen der Pflanzen und Blumen, aus, denen die Puppen gefertigt werden sind folgende:

Junge Blätter der Arenpalme (djanur aren); Curcas multifida (godong pangpung): Curenligo recurvata (godong tlotoh); Tagetes patula, Compositae (kĕmbang kĕnikir); Graphalium longifolium Bl. Compositae, (kĕmbang tinålajoe); Buddheia asiatica Lour., loganiaceae (daun putihan); Iresine Herbstii. Hok. Amarantaceae (daun plåwå). Die letztgenannten vier werden ausschliesslich zur Zusammenstellung der Blumenwedel benutzt, mit denen der Priester beim Gebet das Wasser umhersprengt; die Farben des Wedels sind dann also folgende: Orangegelbe und weisse Blumen, rote und grüne, zum Teil weisse Blätter.

In hohen Ehren steht auf Tosari auch Kjahi Gĕdé Songo Buwono, der Mittstifter und Mittbehüter des Dorfes (Domis nennt ihn wohl unrichtig den Stammvater der Tĕnggĕresen, Seite 129), doch deutet sein Name, besonders in der von Domis gegebenen Form auf seinen Ursprung aus Mataram. vielleicht war er ein Representant des Susuhunan. Sein Grab ligt auf einem Hügel südöstlich von Tosari und an seinem Grabe feiert man jedes fünfte Jahr ein Fest, also am Ende einer Windu (Cyclus von fünf Jahren). Die Schutzheiligen des Dorfes Purwono sind Kjabi Glinding und Kjahi Tugu, erstrer liegt auf dem Kirchhof; die des Dorfes Ngadiwono Kjahi Tunggak und Njai Monjok, welche auf dem Kirchhofe dieses Dorfes liegen und als Stammväter des heutigen Priestergeschlechtes (sieh oben) betrachtet werden und wohl zu den ersten Häuptlingen gehört haben.

1 Vergl. I. H. de Vries: Reis door êenige eilandengroepen der residentie Amboina. Tijdschrift Ned. Aardr. Gen. Ser. II. D. XVII. 1900. Auf der Insel Roma werden auch ähnliche Puppen verehrt, so auch auf Kisser, es ist also wohl eine Indonesische Sitte. 
Der Ahnencult ist also sehr verbreitet. An eine Seelenwanderung in dem Sinne, dass der Geist eines Verstorbenen in folgenden Geschlechtern oder in Thieren weiter leben könne, finden sich hier nur schwache Anklänge. Sie glauben nämlich, dass der Geist eines schlechten Menschen in die Seele des ersten nach seinem Tode in seiner Familie geborenen Kindes ïbergehe, wodurch dieses fortwährend weine; gäbe man dem Kinde dann den Nachlass des Verstorbenen dann schweige es, was für sie ein unumstöslicher Beweis für ihre obengenannte Vermutung ist. Bei jedem Dorfe, oft unweit einer heiligen Grabstätte, stets in der Mitte einer alten Baumgruppe liegt ein heiliger Ort, der nur dazu verwendet wird um die obengenannten Puppen (Bilder der Vorfahren) nach den Festen zu verbrennen. Solch eine heilige Stelle heisst Kebujutan, dort haust unter den grossen Bäumen Kjahi Tugu Pĕdanjangan und neunt man die Gruppe grosser Bäume auch Pĕdanjangan: der Ort von Danjang.

Unter den Bäumen liegen an einer kahlen Stelle einige Steine vergraben und zwar stets fünf, einer mit Lappen umwickelt in der Mitte, die anderen vier um ihn herum (also Kreuzform); wenn ein Dorf verlassen wird, müssen die Bewohner die Steine ausgrabeu und an einer ähnlichen Stelle neben der neuen Ortschaft wieder vergraben. Wird das Dorf von Unglück heimgesucht (Seuche, Brand, u. s. w.) dann sieht der Hauptdukun nach ob die Steine wohl richtig liegen, ordnet sie, wenn es nötig ist, und dann weicht das Unglück. Sie verehren den Vulkan Bromo (Brama), wie schon die Sagen zeigten, und sie haben recht dass sie in diesem nicht nur die vernichtende Kraft fürchten, sondern auch den Segenspender sehen, denn die Asche des Bromo gab diesem Gebirge seine Fruchtbarkeit und sein gesundes Klima, wie ich an anderer Stelle gezeigt habe. ${ }^{1}$ Ausser dem Bromo verehren sie auch das Feuer. An der einen Seite jedes Hauses liegt der Heerd aus Stein und Mörtel, auf dem früher das Feuer nie ausgehen durfte. Um das Fener herum sitzt stets die Familie, dort nimmt sie die Mahlzeiten zu sich und empfängt ihre Gäste. Es scheint dass man früher den Heerd auch wohl mit Blumen schmückte und dort betete. Wenn durch Unachtsamkeit das Feuer erloschen oder dieses mit den Füssen berührt worden war, dann verliess man das Haus und baute ein neues. Später änderte sich die Sitte (wohl weil das Holz fehlte)

1 Meteorologische waarnemingen, sieh bei Literaturquellen S. 87. 
und musste das Feuer nur dann brennen wenn Menschen im Hause waren. Im Rauch des Feuers, welches das ganze Haus durchzieht, trocknet man Zwiebeln und Mais. Im Feuer verehren sie nach Domis den Feuerschlund des Bromo. Heute wird dem Feuer weniger Beachtung geschenkt und nur eine andere Stelle des Hauses scheint ihm noch geweiht. Sie liegt grade am entgegengesetzten Ende. Dort sicht man ein Gerüst von Bambu, welches einen kleinen Soller trägt (pågo), diesen schmückt man bei Festen mit Blumen und er trägt die Opfergaben für die Götter und Verstorbenen, und dann heisst er Sanggar pamalĕngan (S. 102). Jedes grössere Dorf hat einen eigeñen Priester, der Dukun genannt wird. Das Wort Dukun bedeutet hier nicht Arzt wie sonst auf Java, sondern Priester, denn der Dukun hat gar keine medicinischen Kentnisse; am Krankenbette kann er nur beten. ${ }^{1}$ Auf die Abstammung des Priestergeschlechts wurde bei der geschichtlichen Übersicht eingegangen (S. 92-102). Der Priester leitet alle Festlichkeiten , bei denen nur er die Gebete spricht, er bindet und entbindet die Ehen und ist bei allen häuslichen Streitigkeiten der einzige Richter; sie kennen die Zukunft; was geschehen wird, war ihnen längst bekannt ${ }^{2}$. Stirbt er, so kann nur einer seiner Söhne oder einer seiner Verwandten von gleicher Abstammung sein Nachfolger sein, der bei seinem Antritt einen Slamatan (wolo-goro) giebt. Der Dukun bestimmt selbst, welcher seiner Söhne sein Nachfolger sein soll, er wählt meist den, der am klügsten zu sein scheint, durchaus nicht den Ältesten. Streit über diese Thronfolge scheint nie vorzukommen. Der Dukun von Tosari war, soweit wir

1 Die Bedeutung des Wortes Dukun, das sonst einen Arzt bezeichnet, ist den Tĕnggĕresen doch nicht ganz unbekannt da man mich, weil ich allen gerne ärztliche Hülfe leistete den „Dukun Tĕnggěr” (Arzt des Tenggergebirges) nannte.

2 Die Einkünfte des Priesters beruhen besonders auf seinem Gewinn bei dem grossen Todtenfest (Njewu) und dem Neujahrsfest (Karo) wie weiter unten erwähnt werden wird (S. 140). Weiter erhält er für eine Eheschliessung zwei Gulden und für eine Scheidung zwei und einen halben Gulden. Auch besitzt er eigne Ländereien und Kaffeepflanzungen. Wenn er bei Streitigkeiten und Diebställen Recht spricht dann wird er für seine Mühe nicht entschädigt. Aus allem geht hervor dass er in den Augen des Volkes das eigentliche Oberhaupt ist, die Dorfsbeambten (petinggis) sind eine von der colonialen Regierung eingeführte Neuerung und interessieren diese uns darum hier nicht. AIs charakteristisch für diese Bevölkerung verdient nur erwähnt zu werden dass Streitigkeiten bei der Wahl eines neuen Dorfsoberhauptes, die die Regierung ihnen frei lässt, nicht vorzukommen pflegten. Gerne wählte man die Person, welche vom Vorgänger angewiesen wurde. 
wissen, stets der Hauptpriester, ich glaube aber dass Häuptling und Priester früher in einer Person vereinigt waren und dass der erste Priester wie der erste Häuptling früher weiter südwestlich wohnten, wohin auch der Stammbaum der Dukuns zeigt (sieh Seite 93). Dieser Hauptpriester verwahrt in einem Bambuköcher alte Kleider (djimat Klontongan), die dem ersten Häuptling oder, wie sie heute sagen, Batoro Guru zugehört haben sollen. In diesem Köcher, dessen Inhalt nur einmal im Jahre gezeigt wird liegen viele alte Chinesische (Anamitische, etc.) Münzen, die als Djimat's (Amulette) von der Bevölkerung gekauft werden und die sich in dem Köcher stets vermehren sollen, sodass der Vorrat niemals endet. Auch einige Familien besitzen noch Schuüre solcher Münzen (satak), die als Zaubermittel bei manchen Gelegenheiten benutzt werden. Auch legt man sie zu den Opferspenden (Sandingan) ${ }^{1}$. Weiter besitzt jeder Priester einen ewigen Kalender, ein kleines Brett mit vielen Strichen und Punkten. Da dieser und die darauf gegründete Zeitrechnung der Tĕnggĕresen von kundiger Hand ausführlich beschrieben worden ist ${ }^{2}$, so will ich hier nicht näher darauf eingehen und nur erwähnen dass bestimmte Tage für bestimmte Verrichtungen eine gute oder eine schlechte Bedeutung haben können, wodurch der Kalender grossen Einfluss hat auf das tägliche Leben ${ }^{3}$. Jeder Priester besitzt einen bronzenen Becher (Prasen), das sind die Zodiakbecher, denen Millies und ich eine Arbeit widmeten. Sie werden als Weihwassergefässe bei jedem Gebete der Priester benutzt; als Wedel bedienen sie sich eines kleinen Bouquets ron heiligen Blumen (sieh S. 132). Sie sprengen das Wasser umher um alles in-und auswendig zu reinigen. Ein zweiter Becher (Padupan) ohne Zeiohen und von anderer Gestaltung wird benutzt um Weihrauch, "Dupå" +, zu verbrennen, was auch

1 Man findet diese alten Münzen auf ganz Java und auch im Tĕnggĕrgebirge häufig in der Erde beim Bearbeiten der Felder. Es sind runde Münzen mit einem viereckigen Loch in der Mitte um welche Chinesische Schriftzeichen stehen.

2 Over de Tijdrekening der Tenggerezen. Bijdragen tot de Taal-, Landen Volkenkunde. IV ${ }^{e}$ Reeks. $3^{\text {de }}$ Deel. 1879 und Hageman 1. c.

s An einem der Unglückstage, dem Tage Dite pahing kala masuhan der wuku galugan, müssen alle, besonders aber die Priester, ihre Kleider waschen und den Körper reinigen; oft reinigen sie den Körper nicht, sie sind sehr schmutzig in Gegensatz zu den Javanen.

4 Menjan ist der Milchsaft der Styrax benzoë, und bildet den Hauptbestandteil des Weihrauchs: Dupå. 
bei jeder Feierlichkeit während des Gebetes geschieht. Als Kleidung trägt der Priester, aber nur bei grossen Feierlichkeiten (Bromo und Karofest, das Kleid Klambi Ontå-Kesumå; dieses ist eine Jacke, welche ganz aus dreieckigen bunten Lappen zusammen gesetzt ist, warum man sie auch Klambi wadjikan nennt. Dabei trägt er eine viereckige Mütze aus gleichem Materiale und ein Gebetsbandelier. Dies wird erst um dem Leib gezogen, dann über die Brust gekreuzt, während die Enden an der Schulter herabhängen; beim Gebete zieht er sie nach vorn und bewegt sie hin und her, wenn er nicht mit dem Weihrauch oder Wedel beschäftigt ist (de Wolff van Westerrode). Früher war die Kleidung der Priester eine andere, denn sie trugen eine weisse Toga oder Hemd mit rotem Gürtel, kurze weisse Hosen und einen weissen Turban; breite gelbe Bänder mit roten Bändchen waren überkreuz um Brust und Rücken geschlagen ${ }^{1}$. Bei kleineren Festen und überall wo er sonst als Priester auftritt trägt der Dukun nur die kleine Schärpe (sampir). Der Priester hat weiter einen Knecht (Lĕgen) und zwar, wenn mehrere Gehöfte zu dem Hauptdorf gehören (einige Gehöfte oder Töchterdörfer sind jetzt grösser als das Mutterdorf), dann muss jedes Gehöft einen Knecht stellen, grosse Dörfer haben auch wohl zwei Legens. Der Kuecht hilft nur bei den Festen oder Ceremoniën in seinem Dorfe. Fr geniesst keinen festen Gehalt doch von dem, der das Fest giebt, erhält er eine aparte Ration der Speisen, bei welcher stets zwei Keteng (ein cent) gefügt werden. Bei grösseren Festen, wie bei der grossen Todtenfeier (Njewu) bekoinmt er nur 25-30 cents, der Dukun oft eben so viele Gulden. Giebt der Dukun ein Fest, was fast jeden Monat einmal geschieht, dann muss er den festgesetzten Tag allen Bewohnern mitteilen, auch muss seine Frau dann mithelfen. Die Legens von Tosari müssen auch alle die weit entfernten Priester anderer Dörfer mit deren Bewohnern zum Bromofest einladen. Das Amt giebt also viel Arbeit bei wenig Lohn, darum

1 Die Ursache der Umänderung der Kleidung soll folgende sein: Einst sah ein höherer niederländiseher Beamter den Djimat klontongan, das alte heilige Kleid in Bambuköcher; da dieses ganz aus Lappen zusammengesetzt ist, machte der Beamte deu Priester darauf aufmerksam, dass diese Tracht wohl für ihn richtiger sei als die weisse. Er gehorchte diesem Wink und seither tragen die Priester das weisse Kleid nicht mehr. Die obengenannte Puppe "Trukå Bumi" trägt aber noch immer das weisse Kleid und den weissen Turban. Für die Badoejs in West-Java ist anch weiss die Farbe der Festkleider. 
wechselt man jedes Jahr, der alte Legen sucht einen neuen, was oft nicht so ganz leicht ist, da wenige Lust zu diesem Amte haben.

Nach den ältesten Nachrichten war die Beschneidung früher den Tĕnggĕresen unbekannt, doch aus Furcht vor dem Spott der anderen Javanen und um die Regenten von Pasuruan zu befriedigen nahmen sie diese Gewohnheit schon 1783 an. Furcht und Zwang brachten sie auch dazu bei Nachfrage zu erklären dass sie Orang slam seien. Trots dieses, jetzt seit mehr als hundert Jahren eiuwirkenden Einflusses des Islam, der sich immer noch im Stillen bemüht die letzten Reste des Heidentums auszurotten, sind sie auch heute noch keine Mohamedaner und hängen an den alten Gebräuchen, die aber immer mehr verfälscht und vergessen werden. Dass die Beschneidung erst spät eingeführt wurde geht auch daraus hervor, dass sie diese Manipulation noch bis zur Mitte dieses Jahrhunderts nicht selbst verrichten konnten sondern dazu Priester aus der Ebene kommen liessen. Viele waren 1835 (Domis, van Herwerden) noch nicht beschnitten. Auch ist es erst unlängst Sitte geworden die Beschneidung mit einen Feste zu feieren, was früher vermieden wurde. Endlich beschneidet man auch heute nicht durch eine Circumcision, wie viele andere Javanen, sondern man macht nur einen kleinen Längsschnitt in die Vorhaut. Die Mädchen werden gar nicht beschnitten. In gleicher Weise zwang man sie lange Zeit den Eheconsens beim Penghulu (Mohamedanischen Priester) zu holen (die Braut ging dann nicht mit), oder die Ehe bei diesem schliessen zu lassen.

Sie fügten sich, aber betrachteten die Ehe erst als geschlossen, wenn sie auch im eigenen Dorfe von ihrem eigenen Dukun eingesegnet worden war; heute wo man sie frei lässt, gehen die echten Tĕnggĕresen gar nicht zum Penghulu.

\section{Feste.}

a. Allgemeine Feste, welche an bestimmten Tagen gefeiert werden. Im ersten Monat Kasa feiert man das Fest der Vorfahren und der schützenden Götter, wobei alle Bewohner sich im Hause ihrer Priesters einfinden (Domis).

Am 14ten Tage des zweiten Monats Karo feiert man das Fest der Todten. Dermo-Kaké-Mojang (Hageman), dieses ist gleichzeitig Neujahrsfest.

Die Feste im vierten (Kapat) und achten (Kawolu) Monat sollen 
den Voreltern gewidmet sein mit Gebeten vor dem Sanggar Pamalĕngan (Domis).

Der siebente (Kapitu) Monat bringt für den Priester die Fastenzeit. Auch der neunte Monat (Kasongo) hat ein ähnliches Fest wie der vierte, siebente und achte für die Geister, die die Wohnungen beschützen (Domis). Die Bedeutung dieser Monatsfeste lässt sich jetzt nicht mehr genau festsetzen, für alle gilt heute dass der Geister von danjang (heiliger Hain), banju (das Wassers in den Bächen), djalan (der Wege), sanggar (Hausaltar, also Hausgeister) und Kebujutan dabei gedacht wird und man dadurch Segen für das Haus, das Dorf, das persönliche Eigentum und die Feldfrüchte erwartet,

Auf dem zwölften Monat (Kasodo) und zwar auf den vierzehnten Tag fällt das Hauptfest, die Feier am Krater des Bromo.

Đa, wie wir oben auseinandersetzten, solche Feste dem Priester Vorteil bringen ${ }^{1}$, so genügen ihm diese grösseren Zusammenkünfte in seinem Hause noch nicht und giebt er darum von Zeit zu Zeit, zuweilen jeden Monat noch ein kleineres Fest den "Slamatan barikan" zum Wohlsein des Dorfes. Der Dukun richtet es her wenn viele Kranke im Dorfe sind, oder wenn er hört dass in der Nähe (z. B. in der Ebene) eine Krankheit ausgebrochen ist, es vertreibt und verhütet also Unheil. Den Tag vor dem Feste fastet der Dukun und geht die ganze Nacht im Dorfe umher, wenn er dann nach Hause kommt und sich ermüdet niedersetzt, nähert sich ihm der Geist des Djimat Klontongan (des heiligen Rocks) und murmelt ihn einige Laute in's Ohr.

Das ist ihm dann ein sicheres Zeichen dass das Fest stattfinden muss. Zu diesem bringen die Frauen zubereitete Speisen in das Haus des Priesters, die Männer steuern jeder elf Keteng ( $5 \frac{1}{2}$ Cent) bei. Nur die letzteren beteiligen sich an dem Schmause, dürfen aber von den Speisen für ihre Angehörigen etwas mit nach Hause nehmen. Der Priester trägt wenig oder garnichts bei, er leitet nur das Fest. Es erscheinen übrigens wegen Raummangel immer nur die Hälfte der Bewohner, die Schmauserei findet vor der Thüre der Priesterwohnung statt.

Auch die Feste des vierten, siebenten, achten und neunten Monats sind gemeinschaftliche Schmausereien im Hause des Priesters, auch an diesen nehmen die Frauen keinen Anteil, die Beiträge

1 Um des Vorteilswillen geben auch die Petinggi's (Dorfs Oberhäupter, Regierungsbeambte) meist jedes Jahr ein Fest die "sedekah desa". 
bestehen aus nicht zubereiteten Speisen. Alle solche Feste (auch Barikan) werden durch ein Gebet eingeleitet, bei dem Weihrauch verbrannt wird. Dieses Gebet ist das Gleiche für die meisten feierlichen Gelegenheiten, doch werden meist einige Worte hinzugefügt oder eingeschoben, die auf die Bedeutung des Festes Bezug haben.

Auf den siebenten Monat fällt die Fastenzeit, es fastet aber nur der Priester. Am ersten Tage dieses Monats muss er seinen Körper reinigen, dann einen Tag und eine Nacht ohne Nahrung bleiben auch darf er nicht schlafen. Während dieser Nacht geht er im Dorfe und dessen Umgebung ganz allein umber, er sucht die eiusamen Wege auf und darf kein Wort sprechen. Weiter fastet er während dieses Monats und zwar wie die Mohamedaner, d. h. er isst nicht vor Sonnenuntergang und dann auch nur Mais und Kartoffelen ohne Salz. Am Ende des Monats muss er wieder einen ganzen Tag nüchtern bleiben und während der folgenden Nacht umhergehen, dabei darf er aber sprechen, wenn ihm Jemand begegnet. Am nächsten Morgen giebt er den Slamatan: "Babar agung" oder "Rakan gĕnĕp". Das Fest ist übrigens denen der anderen Monate gleich; etwas abweichend feiert man den neunten Monat. Die Gäste bleiben (wie beim Barikan) ausserhalb des Priesterhauses wo man einen Sanggar (Hausaltar) gebaut hat. Vor diesem stehen neun Teller mit einem roten Gebäck (aus Reis) und neun Teller mit einem weissen Gebäck (aus Reis). Erst betet der Dukun das gewöhnliche Gebet, darauf lässt er sofort ein anderes folgen, welches er viermal hersagt, für jede der Hauptwindrichtungen einmal; bei diesen Gebeten wird wie beim Njewufest mit der Schelle geläutet, was bei den anderen Monatsfesten nicht geschieht.

Am Ende jedes Windu (Cyclus von fünf Jahren), oder wenn das Geld fehlt um die acht Jahre (achtjährige Windu) giebt der Dukun den Slamatan "Unan-Unan" in seinem Hause und an dem Graben des einen Schutzgeistes, der in der Nähe des Dorfes Tosari begraben liegt (Kjahi Gedé Songo Buwono). Es ist gemeinschaftlich für alle Dörfer der Nordseite des Gebirges, ganz wie das Karofest, aber viel einfacher als dieses, ohne Sodoran oder Vorzeigen des heiligen Rocks. An dem genannten Grabe legt man einen geschlachteten Büffel in ruhender Stellung nieder. Der Kopf des Thieres ist noch an die Haut verbunden, ausserdem sind der rechte Vorderfuss und einige Fleischstücke in der Haut zu finden. Neben dem Thier stehen zwei aus Blumen und Blättern gefertigte 
Puppen (die Akal Bakal). Am Grabe betet der Priester zunächst mit dem Weihrauch in der Hand das gewöhnliche Gebet, dann folgt das Gebet der Todtenfeier, des Njewu 1 .

Wichtiger als alle genannten ist das Karufest, welches man, obgleich es in den zweiten Monat fällt, das Neujahrsfest der Tĕnggĕresen nennt. Es wird dieses nur bei dem Hauptpriester also zu Tosari gefeiert, zu diesem werden nicht nur die Priester und Bewohner der anderen Dörfer sondern auch wie beim Bromofest alle von der Regierung angestellten Beambten eingeladen, die an die Stelle der alten Deınangs getreten sind. Nur beim Karo- und Bromofeste trägt der Priester das grosse Amtscostüm, welches oben beschrieben worden ist. Zum Slamatan Karo, welchen man auch "Dermo-Kaké-Mojang" nennt ${ }^{2}$ steuern alle Bewohner bei und zwar unzubereitete Speisen (besonders Reis und Zucker) und Geld; die beigetragenen Summen können ziemlich beträchtlich sein, z. B. sechzig bis hundert Gulden für jedes Dorf, da jeder Mann einen halben Gulden beitragen muss; was der Dukun nicht zu dem Feste verwendet, behält er selbst. Das Fest dauert aber auch stets drei Tage, zwei Tage Bajuban (Tänze), am dritten Tage Sodoran (Stechspiel). Die Tänze, früher von den Tĕnggĕresen selbst getanzt, werden heute ganz den gemieteten Tänzerinnen überlassen. Auf diesem Fest liebt man es auch einander Rätsel aufzugeben, die Rätsel werden mitgeteilt und beurteilt durch einen Rat von vier alten Männern, wie bei den alten Hochzeitsgebräuchen erwähıt wurde S. 111. Die Titel dieser Männer sind jetzt oder sind wenigstens auf Tosari andere als die oben genannten: Den Vorsitz hat der Dukun, die auderen drei nennt man Dendang, Kerti djojo und Tungur. Die Strafe für nicht richtige Lösung ist nur ein allgemeines Geschrei und Gelächter um den schlechten Rater zu beschärnen. Besonders bei diesem Fest trinkt man den Saft der Arenpalme (Badĕg arĕn oder Werak arĕn), den man bei solchen Gelegenheiten Sadjĕng nennt(Vergl.S. 111). Ein grosser Topf (Pengaran) ist mit dem Getränk gefüllt, aus diesem schöpft man mit einem Gajong. Dies ist ein hölzernes Gefäss an einem langen Stiel um auch den entfernt sitzenden Gästen einschenken zu können. Das Gefäss (wie ein kleines Tönnchen) hat nur eine kleine Öffnung

2 Kaké is Grossmutter und Mojang Urgrossmutter, es ist also das Fest der Voreltern, der Verstorbenen.

1 Ich habe den Inhalt dieser Gebete fortgelassen weil sie ganz sinnlos sind. Downloaded from Brill. com๑4/26/2023 $02: 37: 15 \mathrm{PM}$ 
damit nicht zu viel gleichzeitig herausfliesse, auch diese Gajong's sind durch Alter und Rauch ganz geschwärzt. Man trinkt aus einem Kuhhorn wie oben erwähnt wurde.

Das Stechspiel wurde oben bei den Hochzeitsgebräuchen schon erwähnt. Zwei Gruppen von Männern, in ihren besten Kleider gehüllt, mit Krissen (Dolchen) im Gürtel, stehen einander gegenüber, plötzlich fällen sie die Lanzen, gehen im Tanzschritt auf einander loss, machen dann einen Ausfall mit den Lanzen, stechen aber immer an den Gegnern vorbei. In diesem Augenblick erheben die Zuschauer ein gewaltiges Geschrei und die Kämpfer schütteln mit den Lanzen, wodurch der Lärm zunimmt, denn die hohlen Bambulanzen sind mit trocknen Maiskörnern gefüllt. Dann weichen sie zurück; dieses Spiel, wie Anfall und Flucht, wiederholt sich noch viele Male, aber stets in gleichmässigem Tempo, wobei der Gamelan sich ununterbrochen hören lässt. Dann steigt der Dukun auf den Soller, wo er den Djimat Klontongan (den Köcher mit dem alten Priesterkleide) verwahrt, trägt ihn hinab und setzt ihn auf die Bank. Dann nimmt er das Kleid und die alten Münzen heraus, murmelt ein Gebet und beräuchert das Kleid mit Dupå. Dann können die Gäste von den alten Münzen (Djimat) einige für kleine Silberstücke kaufen, sie sollen Glück bringen. Dieser Schluss der Feierlichkeit fällt immer auf die Mittagstunde des dritten Tages.

Zwei oder drei Tage nach diesem Feste fangen die anderen Tĕnggĕresen an dem Vorbilde des Dukuns zu folgen, indem sie auch ein Fest, jeder in seinem Hause, geben, und da sie es vermeiden alle an einem Tage zu feiern, so ist der ganze Monat der Freude gewidmet.

Zu diesen Festen backt man Kuchen, "Djenang", die aus Ketan (kleberiger Reis gebacken werden), und jeder, der ein Fest giebt, schickt einige Kuchen an seine Verwandten und guten Freunde, der Dukun erhält stets auch seinen Anteil, sodass der Dukun in diesem Monat soviel Kuchen erhält, dass sie dem Vieh vorgeworfen werden. Diese Karofeste sind speciell den Verstorbenen gewidmet darum sieht man in jedem Hause bei der Feier die oft genannten Puppen aus Blättern und Blumen, auch bei dem ersten Feste im Hause des Oberpriesters. Die Puppen nennt man "Sekar Kentjono agem ageman", sie sitzen in einer mehrere Meter langen Rẹihe auf schmalen Kissen, die auf die lange Bank des Hauses (Amben) gelegt werden und mit weissen Tüchern bedeckt sind. 
Die Art und die Menge der vor den Puppen stehenden Speisen ist genau vorgeschrieben:

$1^{\circ}$. Sĕgå golong. (Reis in kleinen halbeiförmigen Haufen) . $2 \times 22$ Häufchen

$2^{\circ}$. Sĕgå lungguh (Sitzender Reiss, kleine Reiskuchen)

3․ Sĕgå tumpeng (Reis in Kegelform)

$4^{\circ}$. Pasung (Gebäck in Tütenförmigen Blättern)

5 . Năgåsari (Gebäck aus Pisang u. s. w. in viereckigen Päckchen) .

\section{$.2 \times 22 "$ \\ $22 \quad 1$ \\ 22 Stück.}

$22 \quad$

$6^{\circ}$. Djĕnang (Gebäck aus Kĕtan in viereckigen Päckchen).

7 ${ }^{\circ}$. Pisang (Bananen) $22 "$ $22 "$

8. Kĕmbang (Blumensträusschen aus heiligen Blumen) . . . . . . . . . . . .

$9^{\circ}$. Kĕtan (kleine Häufchen klebriger Reis $=$ tĕtĕlan)

10. Djadjan (trockne, kleine Kuchen). . . .

$11^{\circ}$. Djangan (verschiedene Sorten Gemüse) . .

12. Rakan (zwei Presentierblätter "pras = tempé" mit allerlei Gebäck und Früchten gefüllt)

13. Ajam (zwei geröstete Hühner).

Eins der Presentierblätter mit Inhalt und 10 Cent und eins der Hühner ist für den Dukun, der auch 22 von den 44 Segå gollong und Segå lunguh erhält.

Sowie der Dukın in's Haus tritt begrüsst ihn der Herr des Hauses mit den Worten: Dukun purun slamatti; saghabab Adjisoko; saghabab nabi mohamad, kang moho sutji. Und dann bittet er den Dukun dass er das Fest mit einem Gebet einleite. Dieser setzt sich zum Beten nieder mit einem Stück Dupå (mĕnjan) in der Hand, welches er am Schluss des Gebetes in der vor ihm stehenden mit Reisstroh (Merang) gefüllten Weihrauchschale verbrennt. Wie alle anderen ist auch dieses Gebet eine Formel, die dem Klange nach hergesagt wird.

Nach Ablauf des Festes werden die oben genannten Puppen auch wieder verbrannt. Einige Tage nachher bringt man verschiedene Speisen zum Kirchhof, die man auf die Gräber der Familienglieder niedersetzt, um sie dort mit den Verwandten und Freunden zu verzehren.

l. Das Bromofest. Unter den Sagen wurde bereits mitgeteilt. 
wie dieses Fest entstanden sein soll. Warum der Berg den Namen Brama's erhielt weiss man nicht und wodurch die in der Sage erwähnten ersten Tĕnggĕresen auf den Gedanken kamen, dass sie durch Opferspenden an den Bromo, ihre Wünsche erfüllt sehen würden, weiss man eben so wenig. Die Opfer werden wohl aus Furcht entstanden sein, um die in dem Krater gedachten Geister (Naturkräfte), die sich bei den Ausbrüchen schädlich zeigten, zu beschwichtigen und aus dem in den vorhergehenden Blättern mitgeteilten geht wohl zur Genüge hervor, dass die Feuerverehrung bei der des Kraters eine grosse Rolle spielt. Darauf deutet auch die Erzählung hin, dass das ewige Feuer, welches immer in den Hütten brennen sollte, einmal erloschen sei, sodass die armen Tĕnggĕresen ganz ohne Feuer waren um die Speisen zu kochen und sich zu erwärmen. Da habe der Bromo sich ihrer erbarmt, hei einem heftigen Ausbruch habe er Feuer ausgeworfen, wodurch sie das Herdfeuer wieder anzünden konnten, sie nennen dieses Ereignis "Ganti Gĕni".

So war es in den Augen der Priester denn auch kein günstiges Zeichen als der Krater mehrere Jahre lang so zur Ruhe gekommen war, dass sich ein Meer darin bilden konnte, und als nun einige Tage nach dem Bromofest des Jahres 1841 ein heftiger Ausbruch folgte, der die ganze Bevölkerung mit Schreck erfüllte, beruhigten sie die Priester mit der Erklärung dass dies ein Zeichen der unmittelbaren Nähe der Gottheit (Sunan Ibu) sei, welche sich entfernt hatte, als das Wasser im Krater stand, und nun durch ihre Erscheinung gleich nach dem Feste dem Volke besondere Gnade erzeige (van Herwerden). Domis behauptet dass bei dem Opferfest am Bromo die folgenden Gottheiten verehrt würden. 1 Das höchste Wesen "Ingluhur". 2 "Prabu Guru Wenang Bromo". 3 "Prabu Guru Wiseso Visnu". 4 "Prabu Guru Tinangonarang Siwa", dieses seien die höchsten Götter; als Beschirmer des Gebirges würde danu auch noch der folgenden drei gedacht. "Sunan Rodjo Pati", "Sunan Dewo Pati", "Sunan Ibu". Van Herwerden nennt wieder andere Namen, nämlich: "Dewo Sanjang Tunggal", der höchste Gott, "Pandu Dewo Notto" und "Sunan Ibu". Mir wurden von dem Oberpriester folgende Geister genannt, welche in der Nähe des Kraters oder in demselben wohnen sollen (die obengenannten wurden dabei nicht mehr erwähnt).

Am Fusse des Bromo steht eine kleine Hütte, bei der sich das Volk versammelt; in dieser Hütte haust der Geist von "Suuan 
Pernoto", unter dessen Schutz auch der nahe Hügel der Wünsche oder des Steinwurfs (Watu balang) steht. Sunan Pernoto achtet darauf dass alle Priester beim Feste anwesend sind. Steigt man nun an der Leiter zum Krater hinauf, dann muss man daran denken dass dieser Weg "durch Sunan" Perniti bewacht wird, der nicht duldet dass man auf halbem Wege zurückkehrt (van Waey). Auch duldet er nicht dass ein Priester beim Aufstieg fehlt, warum sie stets alle gleichzeitig nach oben steigen.

Am Rande des Kraters wohnt "Sunan Penunggak", der darauf achtet dass die Leute nicht in den Bromo fallen. Steigt man in den Krater hinab, dann kommt man in das Reich des "Sunan Dewa Kesumo", der die Opfer in Empfang nimmt (Vergl. S. 100) und sie dem in derTiefe des Kraters hausenden "Sunan Lelabuh" überreicht. Dieser erhört die Gebete, wofür er die Spenden erhält. Er wohnt übrigens nicht allein im Krater denn "Sunan Tengu" und "Sunan Anteng" halten ihm Gesellschaft. Ein andere Sage (v. Herwerden) erzählt dass der Krater durch einen unterirdischen Gang mit einer Quelle in der Nähe von Winongan in Verbindung stehe; durch diese sollen auch die bei dem ersten und einzigen Menschenopfer in den Krater geworfenen Kinder (sieh Seite 100) wieder an's Tageslicht gekommen sein. Es muss dies übrigens eine neue Abänderung der Sage sein, denn die Kinder wurden der Erzählung nach in Mekka erzogen und brachten den Islam nach Java.

Wahrscheinlich versuchten die Priester ihr Ansehen auch dadurch zu behaupten dass sie den Islam, als von Tĕnggĕresen eingefülırt, in den Augen des Volkes seiner Macht entkleideten. Auf den unterirdischen Gang deutet auch Burer hin, der uns ganz treuherzig erzählt, dass man in der genannten Quelle und dem daraus hervorgehenden Flusse, "Winongan" zuweilen die gebratenen Hühner und Enten treiben sehe, welche die Tĕnggĕresen dem Krater geopfert hätten.

Wir erwähnten bereits, dass das Bromofest im $12^{\text {ten }}$ Monat des Jahres (Kesodo) gefeiert wird und zwar bei Vollmond, meist in der Mitte des Monats. Der Oberpriester bestimmt den Tag und teilt ihn allen Priestern des ganzen Tĕnggĕrgebirges durch seine Legens mit. Am vorhergehenden Abend bereitet man die Opfer und diese werden durch die ältesten Familiënglieder unter das kleine Dach oder Tratag (traptrap) vor die Hausthüre gesetzt (van Waeij). In dem Haus des Demang schlachtete man früher eine Kuh, und legte den Kopf mit Blumen geschmückt unter den Hausaltar (Sanggar, 
Seite 102) urid spendete dem Kuhkopf Opfer nach der Rückkehr von dem Bromofest (Domis).

Schon in aller Frühe ziehen die Leute bei Mondenschein nach dem Bromo, alle in ihren besten Kleidern, Männer, Frauen und Kinder. Viele sitzen zu Pferde. So erreichen die Bewohner von Tosari den Mungal, 1 wo man hinabsteigt zum Sandmeer; dort hausen, wie oben erwähnt wurde, die Geister der Verstorbenen unter der Aufsicht von Raden Demeling bis sie durch das Todtenfest in den Bromo eingehen können. Vom Mungal steigt man 800 Fuss abwärts und gelangt so in das Sandmeer. Es ist ein merkwürdiger Anblick diese tausende Menschen in dem riesigen Sandmeer einherziehen zu sehen; von drei Seiten her strömen sie in dasselbe hinein. Die Pferde fallen gleich in Galop, wenn sie nach dem steilen Abstieg die horizontale Fläche erreicht haben, und in wilder Jagd fliegen nun die Reiter durch das Sandmeer dem Bromo zu, der sich 600 Fuss über das fast eine geographische Meile grosse Sardmeer erhebt. Die bunte Farbenpracht der Kleider, die phantastischen Kostüme der Priester, alle die Opferspenden, die man vorbeitragen sieht, geben dem Ganzen ein höchst eigenartiges Gepräge.

Alles sammelt sich dann am Fusse des Kraters, wo die kleine Hütte steht, ein kleiner Markt entsteht dort aus den zusammengebrachten Opferspenden und den Erfrischungen, die ein jeder mitnahm; ein buntes Leben und Treiben, denn Hunderte müssen jetzt ihre Gelübde erfüllen, die sie im Laufe des Jahres thaten. Der eine, dem eine Kuh erkrankte, gelobte diese, wenn sie genäse mit weissem Papier um den Hörnern zum Bromofest zu bringen; der andere versprach aus irgend einem Grunde dort einen Tanz auszuführen, allein oder mit seinen Familienmitgliedern; ein dritter lässt eine Pantomine durch Tänzerinnen tanzen.

Andere eilen zum Hügel Watu balang (balang $=$ werfen, also Wurfstein); dreimal umkreisen sie diesen, dann nehmen sie einen Stein, stellen sich an die dem Bromo zugekehrte Seite und werfen ihn über den Hügel hinweg, dabei sprechen sie ihren Herzenswunsch aus und zwar ganz laut, sodass man die ernstesten und lächerlichsten Dinge hört. Vorher hat man übrigens seinen Wunsch dem Dukun mitgeteilt, der ihm durch ein kurzes Gebet Kraft verlieh. Die Priester sitzen in einer langen Reihe auf feingefloch-

1 Die Bewohner des Probolinggoschen Tĕnggĕr's steigen vom Djurang pĕnganten in das Sandmeer hinab, die vom Tumpangschēn oder Malangschen Tĕnggěr vom Ider-Ider.

6e Volgr. IX. 
tenen Matten; hinter ihnen sitzen die Legen und beschützen ihre Köpfe mit grossen Sonneuschirmen. Vor jedem steht ein Weihrauchbecher mit Dupå und der Zodiakbecher mit Wasser. Alle schweigen bis der Oberpriester erscheint ${ }^{1}$ und sich zu ihnen setzt, dann fangen sie an zu beten, wobei Weihrauch gebrannt und in gewissen Zwischenpausen ınit dem Wedel Wasser gesprengt wird. Van Waeij behauptet dass der Inhalt dieser, stets von neuem wiederholten Gebete folgender sei: Bromo wir danken Dir für alle deine Gaben und Woblthaten, womit du uns immerfort segnest, und für welche wir Dir unsere Dankopfer heute anbieten. Segne uns, unsere Kinder und Kindskinder.

Übrigens hört man dann noch andere Gebete, die die Priester auf Wunsch einzelner Personen aussprechen, ihre Hülfe wird von Vielen begehrt, da ihre Fürsprache bei den Göttern an diesem Tage besonders hoch geschätzt wird, auch müssen sie die dem Bromo geweihten Opfer einsegnen und mit dem Wedel bespritzen.

Dann, auf ein Zeichen des Oberpriesters, erheben sich alle, und alle Dukuns ersteigen gleichzeitig, wie oben bereits erwähnt wurde, den Bromo. Es folgten früher nur die Männer und zwar alle ohne irgend welche Bekleidung, die Frauen blieben unten; ob auch die Priester sich beim Anstieg entkleideten wissen wir leider nicht. Auch blieb mir unbekannt ob das "Nackt-sein" bei grossen Feierlichkeiten Indischen oder Indonesischen Ursprungs ist. Wir wissen nur dass bei der Leichenfeier des Sultans von Salaparang (Lombok), der zu den Hindu-Balinesen gehörte, und in Gefangenschaft auf Java starb, auch alle Teilnehmer Männer und Weiber sich ganz entkleideten; auch feiern die Orang Dongo auf Sumbawa jährlich ein grosses Fest (Radju), bei dem alle (Männer und Weiber) nackend sind. Diese Orang Dongo sind Heiden, ob sie auch unter Hindu Einfluss gestanden haben muss noch näher untersucht werden. Heutigen Tages ersteigen Männer und Weiber den Bromo und zwar in ihren besten Kleidern.

Am Rande des Kraters werden die Opfer nochmals vom Priester gesegnet und daun werden sie in den Krater geworfen. Die Opfer sind meist Früchte, Mais, Speisen, Kuchen, junge Hühner, Kokosnüsse, Stoffe, eine vollständige Kleidung, Kupfer- und

1 Wie sehr der Gottesdienst der heidnisch-Sjiwaitischen Tĕnggěresen zu einem Mischmasch geworden ist, geht auch daraus hervor, dass dieser Priester behauptet vom Radja Buddha abzustammen. 
Silbergeld. Die meisten Opfer gelangen aber nicht an den Ort ihrer Bestimmung, denn viele Knaben steigen eine Strecke weit in den Krater hinab und fangen die Opfer auf, die sie sich zueignen, was Niemand verwehrt. Es scheint dass es genügt, dass der Opferende sich des Opfers entäusserte, dass die Geister also nur den Gedanken oder die That würdigen, nicht das Opfer selbst, denn die Handlung ist hier gewissermassen die Essenz des Opfers. 